

\section{DISCLAIMER}

This report was prepared as an account of work sponsored by an agency of the United States Government. Neither the United States Government nor any agency Thereof, nor any of their employees, makes any warranty, express or implied, or assumes any legal liability or responsibility for the accuracy, completeness, or usefulness of any information, apparatus, product, or process disclosed, or represents that its use would not infringe privately owned rights. Reference herein to any specific commercial product, process, or service by trade name, trademark, manufacturer, or otherwise does not necessarily constitute or imply its endorsement, recommendation, or favoring by the United States Government or any agency thereof. The views and opinions of authors expressed herein do not necessarily state or reflect those of the United States Government or any agency thereof. 


\section{DISCLAIMER}

Portions of this document may be illegible in electronic image products. Images are produced from the best available original document. 


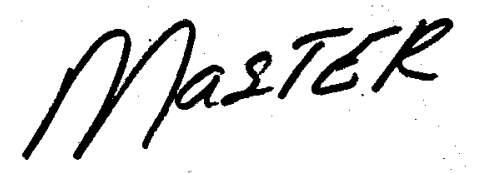

EGG-2078

Distribution Category: UC-66d

\title{
PROTOTYPE GEOTHERMAL POWER PLANT SUMMARY OF OPERATION FOR AUTOMATIC-RUN TEST PHASE
}

\author{
Gregory L. Mines
}

Published February 1981

EG\&G Idaho, Inc. Idaho Falls, Idaho 83415

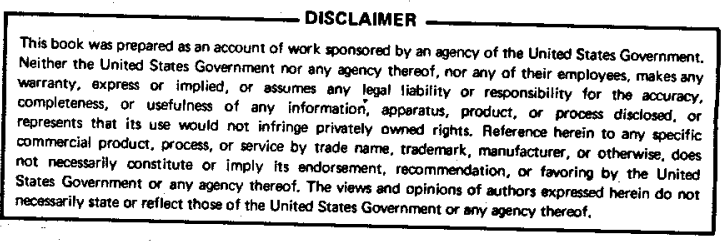

Prepared for the

U.S. Department of Energy

Idaho Operations Office

Under DOE Contract No. DE-AÇ07-76ID01570 


\begin{abstract}
The development of moderate temperature geothermal resources as a viable energy source for electrical power generation is dependent on the development of energy conversion systems and components that can more effectively and efficiently extract the energy from the geothermal fluid. By more effectively utilizing the geothermal resource, the amount of fluid required to produce a given power level is reduced, as are the parasitic power requirements to produce, transport, and dispose of the geothermal fluid, which is reflected

Plant was built to demonstrate and learn the operation of a binary power cycle, and then serve as a test bed for pilot scale components, systems, and/or concepts that have the potential for enhancing the feasibility of power generation from a moderate temperature geothermal fluid resource. This report summarizes the operation to date of the prototype plant, with primary emphasis on the automatic-run phase, during which the plant was operated over a five-month period with minimal operator surveillance.
\end{abstract} in reduced costs of power. The Prototype Power 


\section{ACKNOWLEDGMENTS}

There were many individuals involved in the design, construction, and operation of the Prototype Power Plant whose efforts are greatly appreciated. A special thanks is extended to J.F. Whitbeck and O.J. Demuth for project and technical support, to R.R. Piscitella for engineering support, and to D.G. Cummings for operational support during the automatic-run testing. The efforts of Darryl W. Rogers also merit special acknowledgment. Darryl was responsible for the design and construction of the plant, and its excellent performance during the auto-run test was largely the result of his efforts. 


\section{CONTENTS}

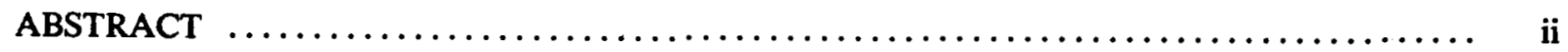

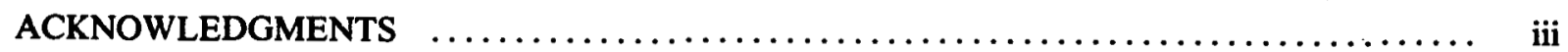

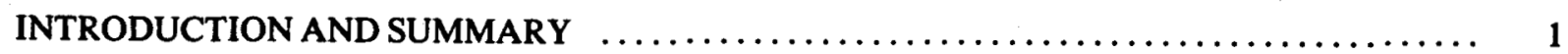

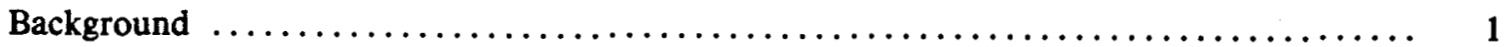

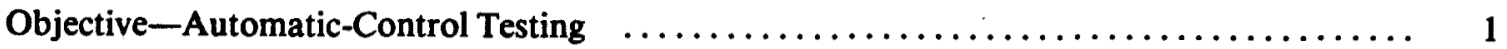

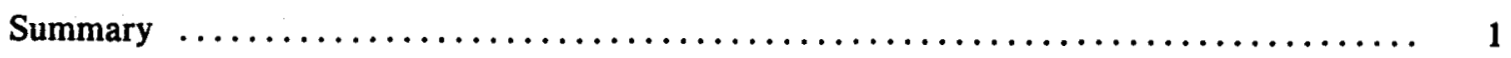

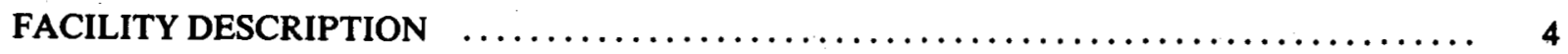

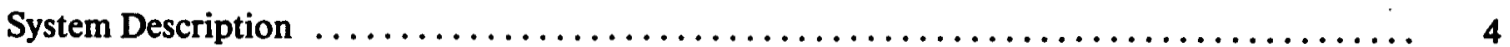

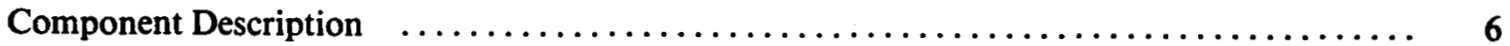

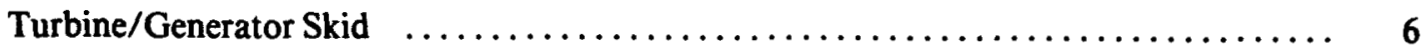

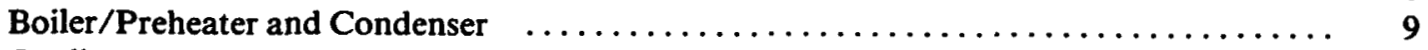

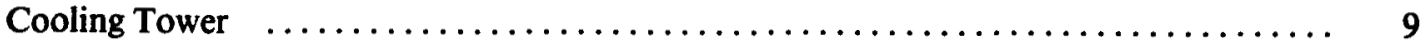

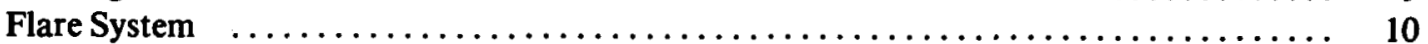

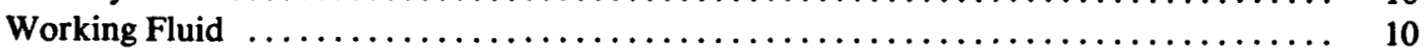

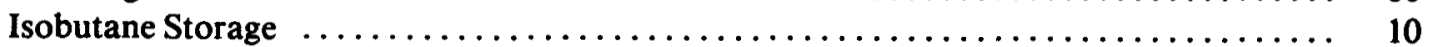

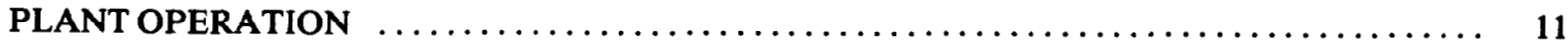

General Operating Method $\ldots \ldots \ldots \ldots \ldots \ldots \ldots \ldots \ldots \ldots \ldots \ldots \ldots \ldots \ldots \ldots \ldots \ldots \ldots \ldots, 11$

Isobutane Fill and Drainback to Operating Levels $\ldots \ldots \ldots \ldots \ldots \ldots \ldots \ldots \ldots \ldots, 11$

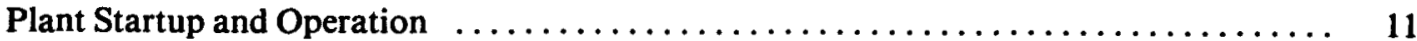

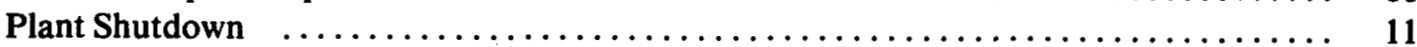

Operating Limitations Encountered $\ldots \ldots \ldots \ldots \ldots \ldots \ldots \ldots \ldots \ldots \ldots \ldots, 12$

Operating Experience $\ldots \ldots \ldots \ldots \ldots \ldots \ldots \ldots \ldots \ldots \ldots \ldots \ldots \ldots \ldots \ldots \ldots \ldots \ldots \ldots \ldots, 12$

Diaphragm Feed Pump $\ldots \ldots \ldots \ldots \ldots \ldots \ldots \ldots \ldots \ldots \ldots \ldots \ldots \ldots \ldots, 12$

Winter Operation $\ldots \ldots \ldots \ldots \ldots \ldots \ldots \ldots \ldots \ldots \ldots \ldots \ldots \ldots \ldots \ldots \ldots \ldots \ldots \ldots \ldots \ldots \ldots, 14$

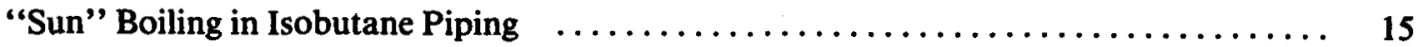

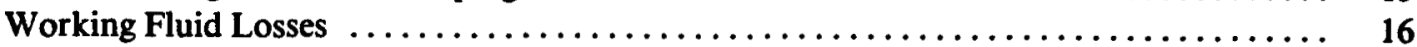

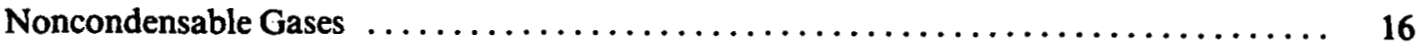

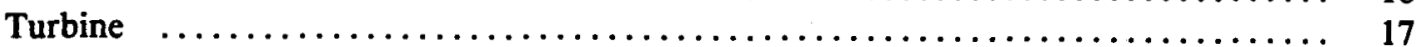

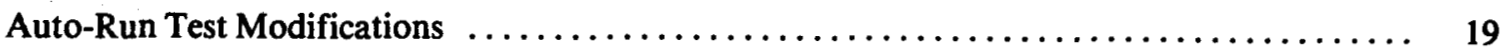

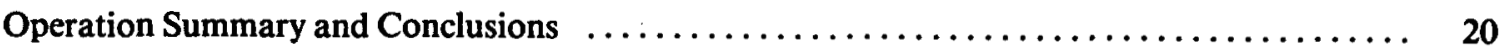

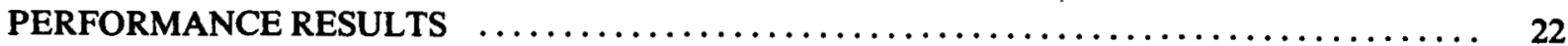

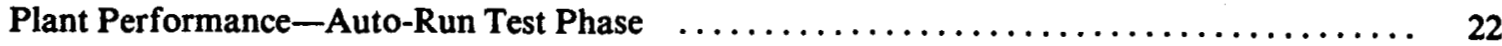




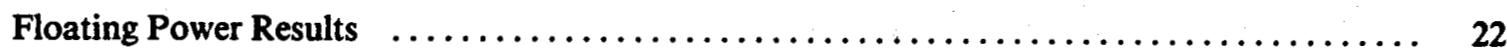

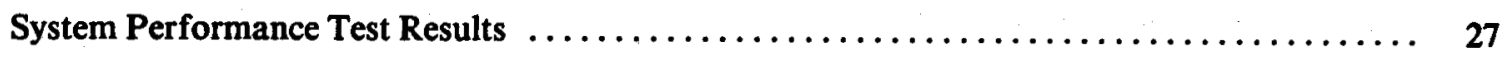

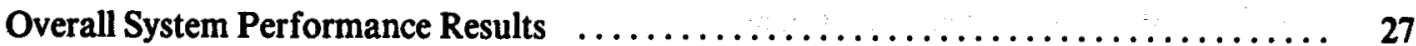

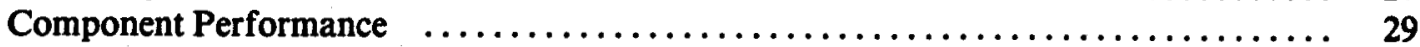

Comparison of Measured and Calculated System Performance $\ldots \ldots \ldots \ldots \ldots \ldots \ldots \ldots \ldots, 32$

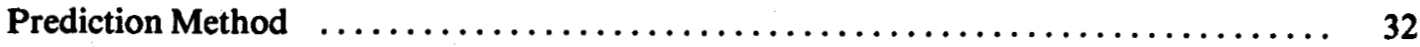

Prediction Example $\ldots \ldots \ldots \ldots \ldots \ldots \ldots \ldots \ldots \ldots \ldots \ldots \ldots \ldots \ldots, \quad 36$

Condenser Degradation-Noncondensable Gases $\ldots \ldots \ldots \ldots \ldots \ldots \ldots \ldots \ldots \ldots \ldots$

Performance Summary and Conclusions $\ldots \ldots \ldots \ldots \ldots \ldots \ldots \ldots \ldots \ldots \ldots \ldots \ldots$

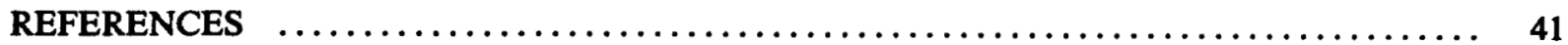

\section{FIGURES}

1. Prototype Power Plant flow schematic $\ldots \ldots \ldots \ldots \ldots \ldots \ldots \ldots \ldots \ldots \ldots \ldots \ldots \ldots \ldots, 4$

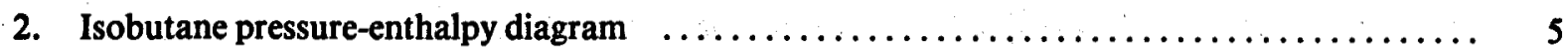

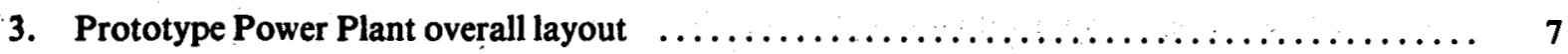

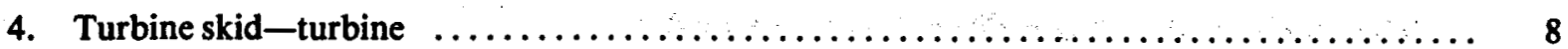

5. Turbine skid-pumps $\ldots \ldots \ldots \ldots \ldots \ldots \ldots \ldots \ldots \ldots \ldots \ldots \ldots \ldots \ldots \ldots \ldots \ldots \ldots \ldots \ldots, 8$

6. Barber-Nichols turbine skid configuration schematic $\ldots \ldots \ldots \ldots \ldots \ldots \ldots \ldots \ldots, 9$

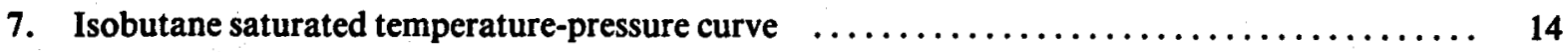

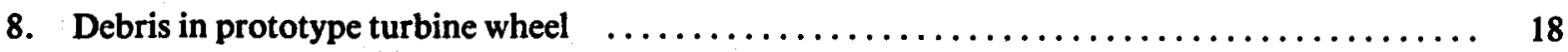

9. Erosion of prototype turbine nozzles $\ldots \ldots \ldots \ldots \ldots \ldots \ldots \ldots \ldots \ldots \ldots \ldots \ldots \ldots \ldots \ldots \ldots \ldots, 18$

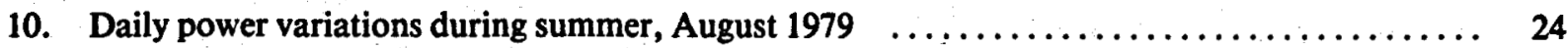

11. Daily power variations during winter, December $1979 \ldots \ldots \ldots \ldots \ldots \ldots \ldots \ldots \ldots \ldots \ldots$

12. Prototype Power Plant cooling tower performance $\ldots \ldots \ldots \ldots \ldots \ldots \ldots \ldots \ldots \ldots \ldots \ldots, 25$

13. Effect of cold temperatures on tower performance $\ldots \ldots \ldots \ldots \ldots \ldots \ldots \ldots \ldots \ldots \ldots, 26$

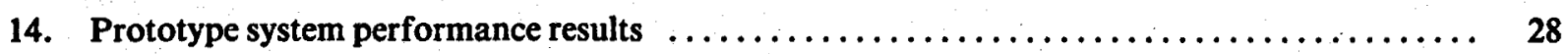

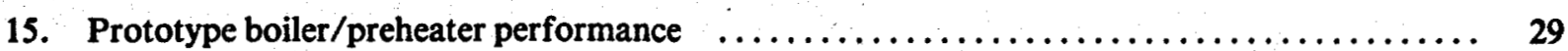

16. Prototype turbine performance efficiency versus velocity ratio $\ldots \ldots \ldots \ldots \ldots \ldots \ldots \ldots \ldots$

17. Prototype turbine performance efficiency versus pressure ratio $\ldots \ldots \ldots \ldots \ldots \ldots \ldots \ldots \ldots$ 


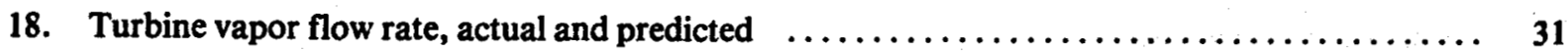

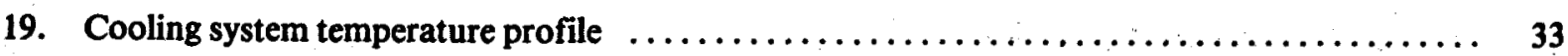

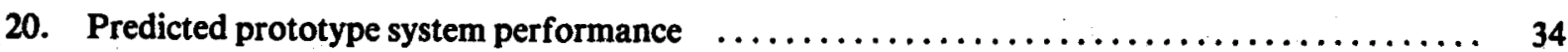

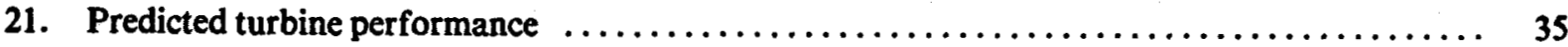

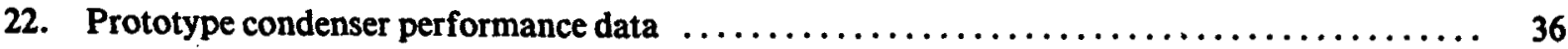

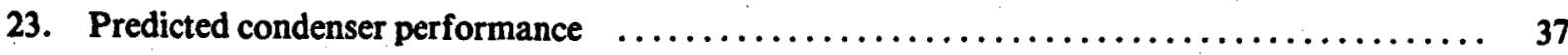

24. Prototype condenser performance degradation due to noncondensable gases $\ldots \ldots \ldots \ldots .38$

\section{TABLES}

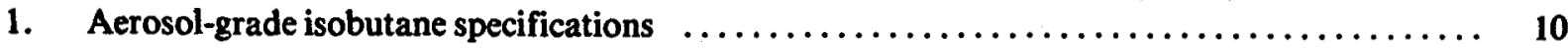

2. Prototype Power Plant operating parameters $\ldots \ldots \ldots \ldots \ldots \ldots \ldots \ldots \ldots \ldots \ldots \ldots \ldots$

3. Prototype Power Plant alarm and shutdown modes, automatic-run modification $\ldots \ldots \ldots .20$

4. Summary of Prototype Power Plant operation during automatic-run test $\ldots \ldots \ldots \ldots \ldots \ldots, 23$

5. Prototype Power Plant working fluid samples, pressure-temperature relationships $\ldots \ldots \ldots \quad 38$

6. Chemical analysis of Prototype Power Plant working fluid $\ldots \ldots \ldots \ldots \ldots \ldots \ldots \ldots . \quad 39$ 


\title{
PROTOTYPE GEOTHERMAL POWER PLANT SUMMARY OF OPERATION FOR AUTOMATIC-RUN TEST PHASE
}

\author{
INTRODUCTION AND SUMMARY
}

\section{Background}

The Prototype Power Plant (PPP) is a pilotscale geothermal power plant located at the Idaho National Engineering Laboratory Raft River Geothermal Test Site. The plant is a test facility to be used to investigate various concepts that have the potential to enhance the commercial production of electrical power from moderate temperature geothermal resources. The size of the plant allows the different components to be replaced with an alternate component that performs the same function but uses an advanced or unconventional design concept. In this way, different concepts can be tested in an operational environment that would closely resemble that of a full-scale plant without the associated costs. The work is being done as part of the Conversion Technology effort being conducted by EG\&G Idaho, Inc., for the Department of Energy, Division of Geothermal Energy.

The overall test program for the PPP consists of several phases in which such variables as automatic control, heat exchange components, and working fluids will be tested. This report covers the initial test phase that was conducted with the plant configuration as initially constructed, using surplus materials for the cooling system and the heat exchangers. The primary emphasis of the initial phase of the test program was the operation of the PPP in the automatic control mode; therefore, this report will accent the operational experience and demonstrate that, within certain limits, the system and component performance are predictable.

\section{Objective - Automatic-Control Testing}

The principal objective of the testing thus far with the PPP has been to obtain operational experience with the plant and its components, and to demonstrate the operation of the plant in the automatic control mode. Operational experience with binary power plants using isobutane over extended periods of operation is limited. In particular, experience is limited for the relatively low geothermal fluid temperature and ambient conditions of the Raft River Site. In the automatic control mode, the plant was to operate with minimal operator surveillance, to control selected plant parameters automatically, and to shut down automatically to a safe configuration in the event of an upset condition that posed a potential hazard to the equipment and/or personnel. This facility also provides a means of identifying potential problem areas that might arise during the startup and operation of the 5-MW(e) Raft River plant so that procedures and/or equipment can be modified accordingly.

In addition to demonstrating the ability of the plant to run unattended in the automatic-control mode, this phase of testing provides component and performance data. One objective of these performance tests was to show the large variations in power output of organic Rankine cycle due to the daily and seasonal variations in the ambient air temperature. This series of performance tests was also to be used to verify, where possible, predicted system and component performance at "design" and "off-design" conditions.

\section{Summary}

The testing of the PPP in the automatic control mode was successful in that all the main objectives of the test were achieved.

1. Plant operation during this period was stable when in automatic control. Although the plant operated considerably off the "design" conditions (2.16 MPa boiler pressure), i.e., boiler pressures ranging from 1.379 to $2.117 \mathrm{MPa}$, the plant was 
able to operate and produce electrical power with minimal operator surveillance and downtime.

2. The operator surveillance required to operate the plant was reduced from $24 \mathrm{~h}$ per day to less than $8 \mathrm{~h}$ per day, the majority of which was required for the collection of data.

3. The plant operated approximately $87 \%$ of the time that geothermal fluid was available.

4. The plant was not able to reach design turbine inlet and exhaust conditions because sufficient geothermal fluid flow and temperature were not available, and because of limitations in the cooling system, specifically the condenser. Extremely cold weather would be required to approach design condensing conditions, and because of icing in the cooling tower, these conditions would be difficult to maintain. Although the plant never achieved design turbine inlet and exhaust pressures (and corresponding velocity and pressure ratios), the turbine efficiencies were equivalent to, and, in some cases, exceeded the values predicted by the manufacturer, the Barber-Nichols Engineering Company, when turbine conditions approached the design values.

5. A maximum plant output of $59 \mathrm{~kW}$ was measured at a turbine inlet pressure of $2.12 \mathrm{MPa}$ and an exhaust pressure of $0.490 \mathrm{MPa}$. The geothermal fluid temperature was $135^{\circ} \mathrm{C}$, and the flow rate was $6.69 \mathrm{~kg} / \mathrm{s}$.

6. The plant performance was predictable, providing. it operated at velocity or pressure ratios near the turbine design point.

7. Power variations due to daily ambient air temperature changes were determined to be approximately 25 to $30 \%$ during the summer and 10 to $15 \%$ in the winter.
The primary operational problems encountered thus far in operating the PPP are summarized below. These problems have been resolved, or their effects on plant performance minimized.

1. The original feed pump in the plant as initially constructed was a diaphragmtype, positive displacement pump. This pump was eventually replaced with a centrifugal pump because of repeated failure of the pump diaphragm. No further problems have been encountered with the feed pump since its replacement.

2. Startup problems were encountered during summer afternoons due to liquid boiling in the pump suction piping. The uninsulated liquid piping was warmer than the insulated condenser due to solar heating of the pipe surfaces. Since the system pressure was controlled by condenser and boiler (both vessels insulated) temperature, heat had to be added to the condenser unit from an external source to raise condenser (and piping) pressures and stop the boiling in the liquid process piping.

3. The major operational problem encountered was the contamination of the isobutane working fluid with nitrogen. This contamination led to a buildup of nitrogen in the condenser, which resulted in higher condenser pressures and lower power output. The nitrogen gas was used to move the working fluid back and forth between storage and the plant. Because isobutane had to be added on a daily basis to the plant while running to make up for working fluid losses from leakage, the storage tank was maintained at a pressure corresponding to or slightly exceeding condenser pressure. This excess nitrogen pressure introduced nitrogen into solution in storage, and it came out of solution once the fluid had been added to the plant. To correct the problem, it is planned to install a charging system in which the nitrogen does not contact the working fluid. Until the charging system is installed, the use of 
nitrogen has been minimized and excess nitrogen pressure vented off storage after charging the plant with working fluid.

This report describes the plant and how it was operated, identifies operational problems, and provides performance results. A description of the binary power cycle and the major plant components and/or systems is presented, and the operation of the plant is reviewed. Included in this review is a brief description of the plant startup and operation and the major operational problems and limitations encountered. Finally, a comparison of the anticipated system and component performance with the actual performance is provided. This comparison also reviews the plant reliability in terms of percentage of time on-line when geothermal fluid was available and illustrates the impact of cold weather on the performance of the plant and heat rejection system. 


\section{FACILITY DESCRIPTION}

\section{System Description}

Although the Prototype Power Plant is considerably smaller than a full-scale plant in size and power output, its major systems are similar. The test facility was designed and built with sufficient flexibility that it can be operated as either a power loop (i.e., producing electrical power) or as a thermal loop (i.e., turbine bypassed). In reviewing the operation of the plant (in a subsequent section titled "Plant Operation), one should remember that the plant is always started as a thermal loop, and brought to steady state conditions before converting to the power loop mode.

The description of the PPP in the power loop mode is more easily understood if one refers to the flow schematic and isobutane pressure-enthalpy diagrams shown in Figures 1 and 2. The flow schematic in Figure 1 identifies major cycle components, but not the auxiliary systems, i.e., fire protection, vent and drain, storage, flare, control, etc. In the current plant configuration, the preheating and boiling of the working fluid occur in a single heat exchanger unit. Hot geothermal fluid is circulated through the tube side of the boiler/preheater where it is cooled as heat is transferred to the working fluid. The isobutane working fluid circulating past the outer tube surface is first preheated to the saturation temperature corresponding to boiler pressure and then vaporized. A separator is located on top of the boiler/preheater to remove any liquid entrained in the boiler vapor discharge. The vapor leaving the boiler is then expanded through the turbine that drives the generator to produce power. In the power loop mode, the turbine bypass valve is closed. The low pressure gas leaving the turbine is discharged to the condenser where the working fluid vapor is cooled and condensed to liquid. Cooling water circulating through the tube side of the condenser is heated by the processes of desuperheating and condensing of the working fluid on the outer tube surfaces. The cooling water is circulated through a wet cooling tower where the heat added in the condenser is rejected to the atmosphere. The liquid working fluid in the condenser is then circulated back to the boiler using boost and feed pumps in series.

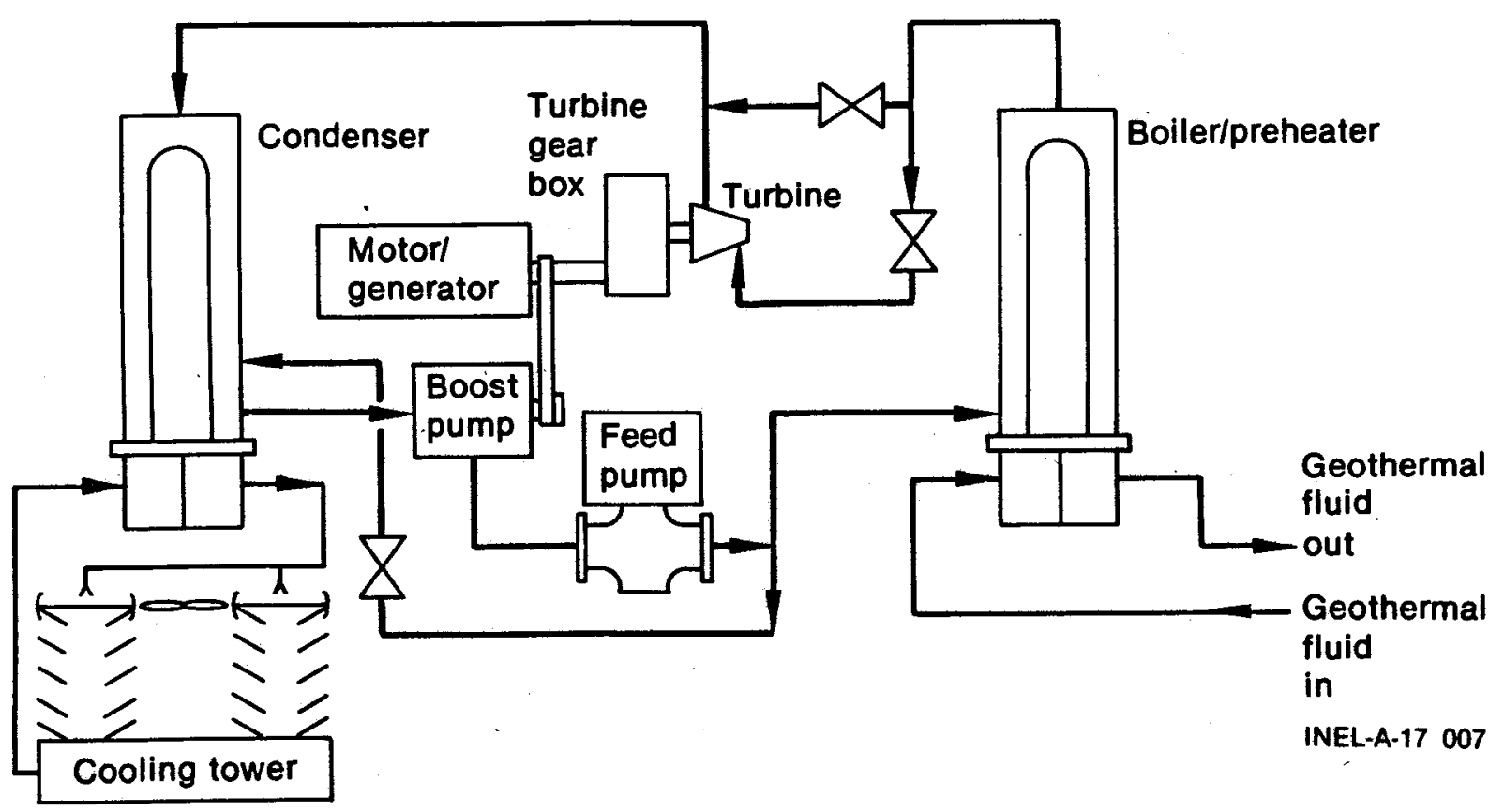

Figure 1. Prototype Power Plant flow schematic. 


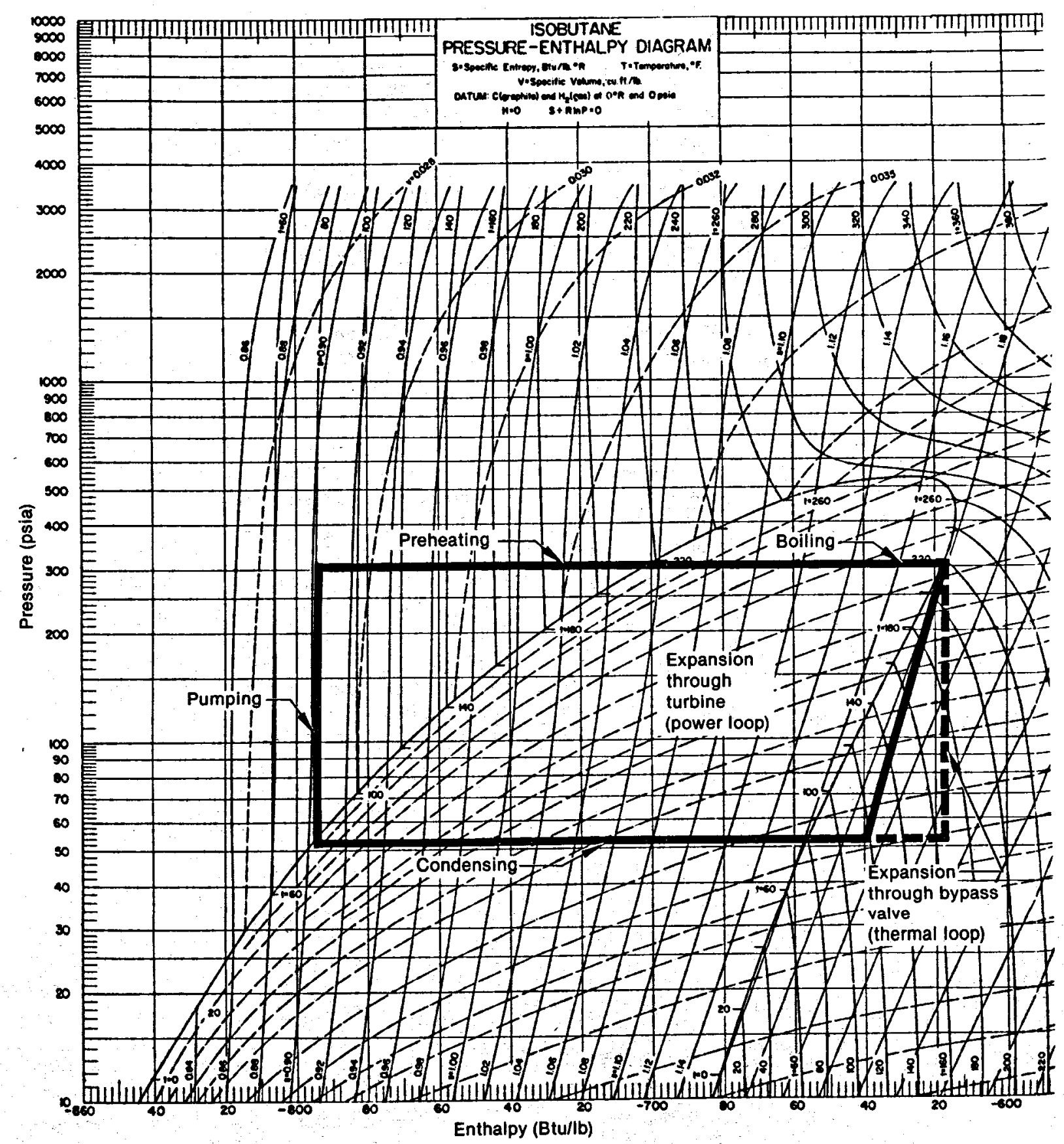

Figure 2. Isobutane pressure-enthalpy diagram. 
The thermal loop operation differs from the power loop mode in that the turbine is isolated and the turbine bypass valve provides the required pressure drop between the boiler and condenser. The thermal loop operation does change system performance, since the condenser heat load is increased due to the increased superheat in the inlet vapor (see Figure 2). This increase in the condenser heat load is the energy that the turbine would have extracted from the working fluid if the plant had been operating in a power loop mode. The net effect of the increased superheat is a small increase in condensing temperature and pressure.

The physical layout of the plant is shown in Figures 3,4, and 5 . The overall layout of the plant is shown in Figure 3, with the major components identified. The two vertical vessels mounted inside the support tower are the condenser and boiler/preheater. The Barber-Nichols turbine skid is shown in the foreground, with the cooling tower in the background. The turbine skid as shown in Figure 3 is the unit as originally installed with the diaphragm feed pump. The current configuration of the turbine skid with the centrifugal feed pump (see the section, "Plant Operation," for further discussion) is shown in Figures 4 and 5.

\section{Component Description}

Turbine/Generator Skid. The turbine/ generator skid was designed and built by the Barber-Nichols Engineering Company of Arvada, Colorado. The skid, as initially constructed, consisted of a turbine, turbine gearbox, induction motor/generator, boost pump, feed pump, and speed reducing gearbox for the feed pump. The pumps and/or their gearbox were driven from the interconnecting shaft between the turbine gearbox and the motor/generator. When the plant was operating as a power loop, i.e., producing electrical power, the turbine provided power to the pumps as well as turning the power-producing generator. During startup and thermal loop operation, the motor provides power to the skid isobutane pumps. A schematic of this skid arrangement is shown in Figure 6. The $60-\mathrm{kW}$ rating for the system is based on this configuration and operation at very low condensing temperatures.

The original isobutane feed pump installed as part of the Barber-Nichols skid was a slow speed, piston/hydraulically driven diaphragm-type pump manufactured by Dyneaco. The pump was rated at $0.0034 \mathrm{~m}^{3} / \mathrm{s}$ and $2.413 \mathrm{MPa}$ at $302 \mathrm{rpm}$. It was driven from the interconnecting shaft between the turbine gearbox and the motor/generator through an intermediate gearbox speed reducer. Because of repeated diaphragm failures (the section titled "Plant Operation" provides further discussion), this pump was later replaced with a high speed centrifugal pump manufactured by Sundstrand. This new feed pump had its own driver coupled to it, so that the feed pump power requirements were no longer supplied by the turbine or the induction motor/generator.

The turbine generator skid as now configured is shown in Figures 4 and 5. A brief description of each of the skid components follows.

Foed Pump-The function of the working fluid feed pump is to provide the head necessary to oyercome boiler pressure and circulate the working fluid through the plant.

The Sundstrand feed pump (Model LMV-322) is rated at $0.0035 \mathrm{~m}^{3} / \mathrm{s}$ at $12400 \mathrm{rpm}$ and $333.8 \mathrm{~m}$. The driver is a $460-\mathrm{V}, 3$-phase, $18.65-\mathrm{kW}$, explosion-proof motor. The assembly has an intermediary gearbox that steps up the driver shaft speed from $3500 \mathrm{rpm}$ to the $12400 \mathrm{rpm}$ pump speed.

Boost Pump-The function of the working fluid boost pump is to increase the pressure of the working fluic leaving the condenser enough to satisfy the net positive suction head (NPSH) requirements of the feed pump.

The boost pump is a multistage centrifugal pump manufactured by Gould Pumps (P/N BP7035-SC-03). The pump was originally equipped with five stages and was rated at $0.0034 \mathrm{~m}^{3} / \mathrm{s}$ at $2400 \mathrm{rpm}$ and $32.9-\mathrm{m}$ head, with an NPSH of $0.91 \mathrm{~m}$. The pump has since been modified (two stages removed) and now develops a $19.8-\mathrm{m}$ head at rated conditions. The pump is driven by a belt reducer from the interconnecting shaft between the turbine/gearbox and the motor/generator.

Turbine/Generator. The turbine is an axial flow type unit fabricated specifically for the prototype plant by Barber-Nichols. It operates at $22470 \mathrm{rpm}$ to give $79.8 \mathrm{~kW}$ output at $2.158 \mathrm{MPa}$ inlet pressure, $0.365 \mathrm{MPa}$ exhaust pressure, and $1.64 \mathrm{~kg} / \mathrm{s}$ saturated isobutane vapor flow driving 


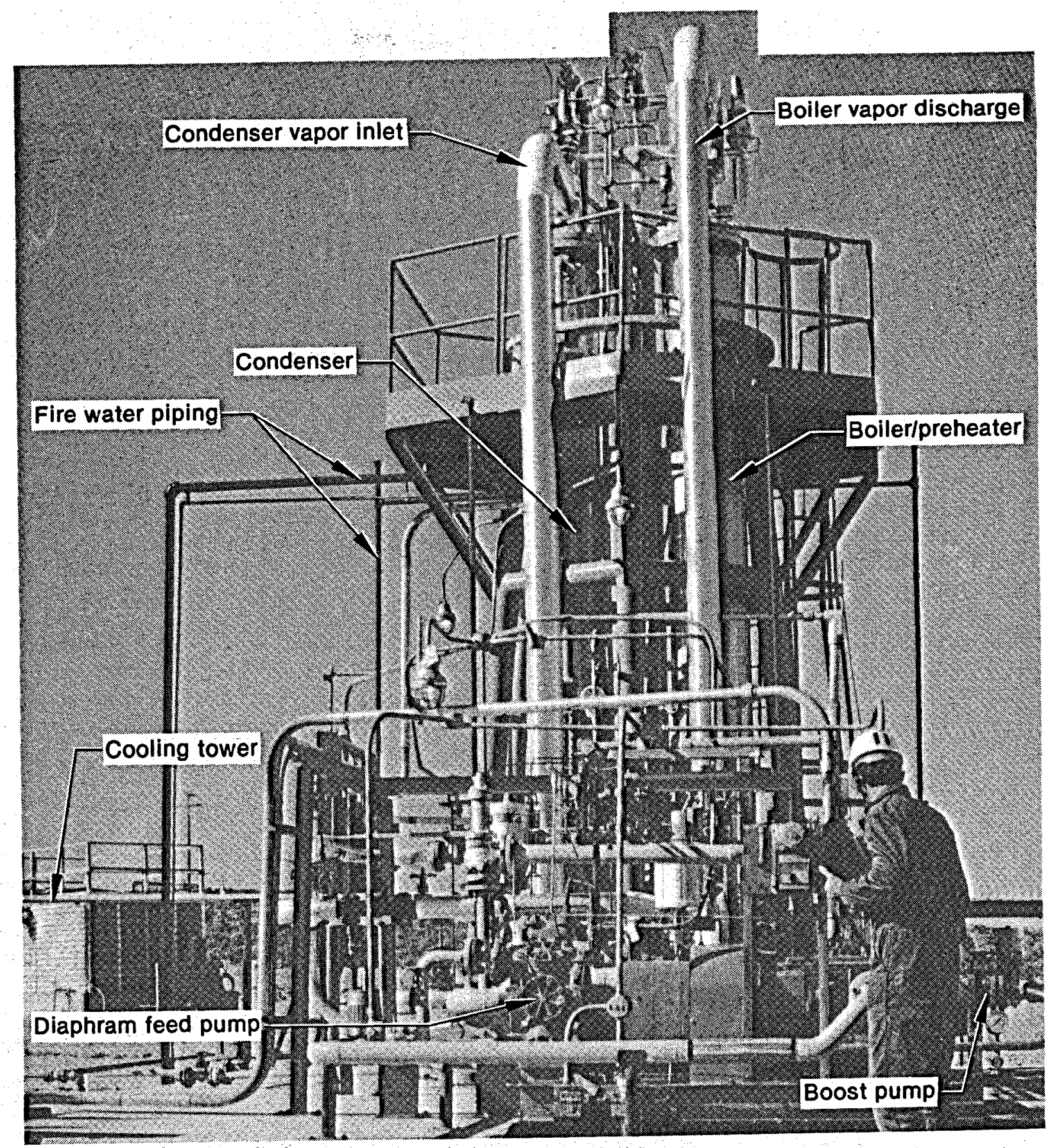

Figure 3. Prototype Power Plant overall layout. 


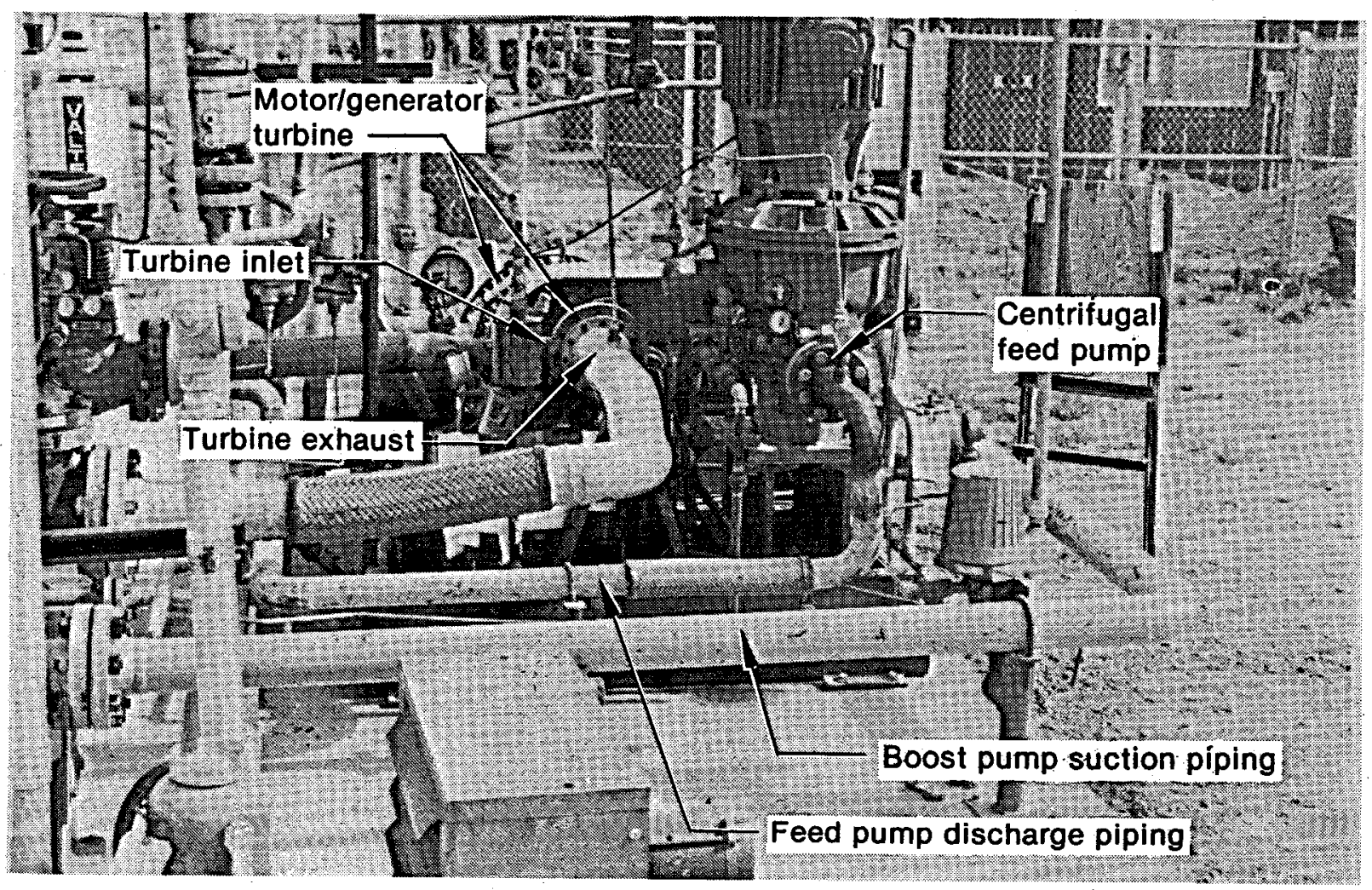

Figure 4. Turbine skid-turbine.

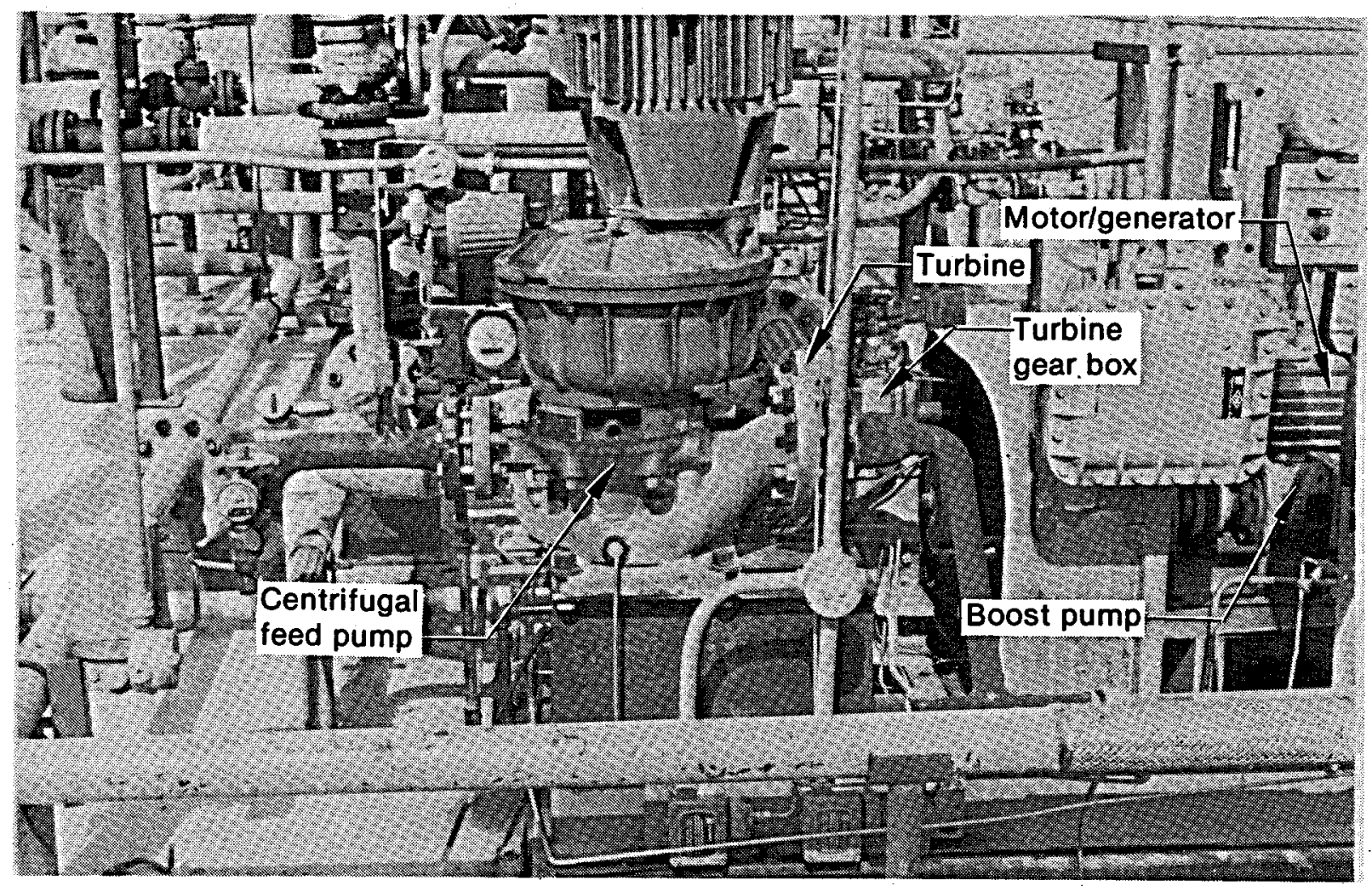

Figure 5. Turbine skid-pumps. 


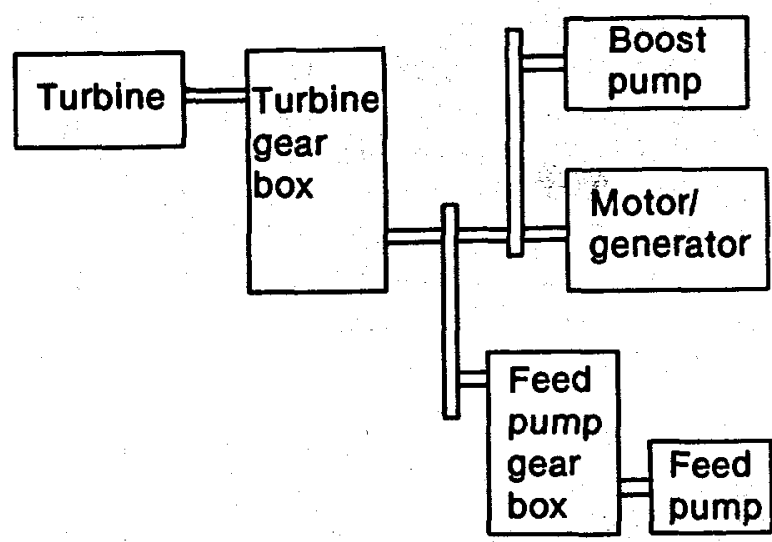

INEL-A.17 008

Figure 6. Barber-Nichols turbine skid configuration schematic.

the induction motor/generator through a gear box. The gearbox has a 6.135:1 speed ratio, giving a shaft output of $3600 \mathrm{rpm}$. The generator is a standard induction motor manufactured by Marathon Electric. The motor/generator has a rating of $74.6 \mathrm{~kW}$ at $3560 \mathrm{rpm}$ and requires (or produces) 3-phase, $440-\mathrm{V}, 125-\mathrm{A}, 60-\mathrm{Hz}$ electrical power. It is explosion proof and fan cooled.

At plant startup or during thermal loop testing, the motor/generator acts as a motor driving the boost pump. During motor operation, the turbine is not driven because the gearbox contains a clutch that does not engage until the turbine reaches operating speed. To bring the plant from a thermal loop to a power loop mode, the turbine is slowly brought up to operating speed; further increase in vapor flow causes the turbine to pick up load, and the motor/generator switches to a generating mode. As more vapor flow at higher pressures is expanded through the turbine, the turbine tries to drive the generator past synchronous speed, producing more power, The power generated is fed back into the local power grid. The induction motor/generator requires no frequency control when operating as a generator because frequency is established or controlled by the power grid being fed.

Boiler/Preheater and Condenser. The prototype plant boiler/preheater and condenser are identical shell and tube heat exchangers (obtained from surplus as a cost savings measure). Each unit contains $33,1.91-\mathrm{cm}$, finned $U$ tubes. They were originally used as aftercoolers on large air compressors. The heat exchangers are constructed with carbon steel shells and nozzle, admiralty brass tubes, and muntz metal tube sheets. The shell side of both heat exchangers is designed for $2.69 \mathrm{MPa}$ at $149^{\circ} \mathrm{C}$. The tube sides are designed for $1.136 \mathrm{MPa}$ at the same temperature. Condenser and boiler surface heaters are installed on the outer surfaces of the units and are used as external heat sources to control the pressure of the plant when it is in a standby condition (containing isobutane).

Both heat exchangers were installed in the vertical position, with the tube U-bend at the top of each exchanger. The water flow (geothermal fluid or cooling water) is through the tube side of each heat exchanger while the isobutane is circulated through the shell side past the outer tube surface. Although the water flow path is similar in each unit, the isobutane path is different. Liquid isobutane enters the boiler/preheater just above the tube sheet (approximately $40.6 \mathrm{~cm}$ above), and is circulated up past the hot tubes until the liquid reaches the saturation temperature corresponding to the boiler pressure. From this point on, boiling occurs with some superheating possible at lower boiler liquid levels. The isobutane working fluid vapor leaves the boiler at the top of the unit. In the condenser, the low pressure superheated gas enters the top of the unit and is desuperheated and condensed as it circulates down past the cold heat exchanger tubes.

The units are capable of producing the design turbine vapor flow of $1.68 \mathrm{~kg} / \mathrm{s}$ and turbine inlet pressure of $2.158 \mathrm{MPa}$ at the design geothermal fluid temperature of $138^{\circ} \mathrm{C}$ and a flow rate of $0.0076 \mathrm{~m}^{3} / \mathrm{s}$. However, condenser surface area is inadequate for obtaining the design condensing pressure of $0.365 \mathrm{MPa}$ at nominal ambient temperatures. Thus, the plant output is limited below the original target of $60 \mathrm{~kW}$ at design geothermal fluid and turbine inlet conditions.

Cooling Tower. The prototype plant cooling tower is a surplus unit obtained from the Idaho National Engineering Laboratory. The tower, manufactured by Marley Cooling Tower Co., is a mechanical draft, cross-flow type. The heat load in the tower is approximately $586 \mathrm{~kW}$ during normal operation of the plant. The tower is equipped with a 22.38-kW Johnson vertical turbine pump, which circulates water through the plant cooling system, and a 3.73-kW fan, which induces air flow through the tower. 
Fiare System. The flare is a John Zink STF-U-4 utility field flare equipped with a flame front generator. It is designed to handle $2.52 \mathrm{~kg} / \mathrm{s}$ gas flow. A burst disk and venting relief valve have been designed into the flare system to eliminate the necessity for a constant inert gas purge. The flare pilot is manually controlled and burns continuously during plant operation, with automatic reignition upon flare failure.

Working Fluid. The working fluid used thus far in prototype testing has been an aerosol-grade isobutane (A-31) provided by Phillips Chemical Company. The specifications for the fluid are given in Table 1.

The pressure-enthalphy diagram for pure isobutane is shown in Figure 2. The critical pressure and temperature of isobutane are $3.64 \mathrm{MPa}$ and $134.8^{\circ} \mathrm{C}$. At one atmosphere $(0.101 \mathrm{MPa})$, sea level isobutane will boil at $-11.7^{\circ} \mathrm{C}$. At one atmosphere of pressure at Raft River $(0.084 \mathrm{MPa})$, isobutane will boil at approximately $-16.1^{\circ} \mathrm{C}$. Thus, during the winter at Raft River, care must be taken to ensure that the system is maintained above atmospheric pressure to prevent leakage of oxygen into the system.

Isobutane Storage. The isobutane storage consists of a buried $(0.91 \mathrm{~m}) 3.785-\mathrm{m}^{3}$ tank. The tank is buried for safety reasons and to provide gravity drainback to storage. The drain system connects all major plant components and process piping low points to the storage tank and is used for filling the plant as well as draining it.

Table 1. Aerosol-grade isobutane specifications

Composition, mole \%

Propane

Isobutane

Normal butane

Pentanes

Total saturates

Vapor Pressure, $\mathrm{MPa}$ at $21.1^{\circ} \mathrm{C}$

Sulfur, ppm

Residue, $\mathrm{g} / \mathrm{mL}$
1.0 maximum

95.0 minimum

5.0 maximum

0.1 maximum

99.9 minimum

$0.315 \pm 0.013$

5 maximum

0.0005 maximum 


\section{PLANT OPERATION}

This section describes a general operating philosophy for the plant and relates some of the operating experience accrued thus far. This section is not intended to be a chronological history of the plant, although some historical background may be required in relating particular experiences. It is intended that the information presented may be of some use to designers and operators of geothermal binary plants, although in some instances, the information may be specific to the PPP.

\section{General Operating Method}

Isobutane Fill and Drainback to Operating Levels. In a full plant shutdown, the isobutane working fluid system is drained back to storage and maintained at minimum positive pressure with a nitrogen blanket to prevent any contamination of the system with oxygen. A prerequisite for draining back to storage or filling the plant is that the flare pilot be ignited. To bring the plant up to an operating condition, the isobutane system is first liquid filled. This is accomplished by pressurizing the isobutane storage tank with nitrogen, thus forcing fluid out of the tank and into the plant. During the fill process, the system is maintained above the fluid saturation pressure to prevent isobutane boiloff, thus minimizing working fluid losses to the flare system. Each component in the plant is vented, at its high point, to the flare system until that component is liquid full.

To drain the plant back to operating levels, excess nitrogen pressure is vented from the storage tank until the tank pressure is slightly above the saturation pressure of the fluid in storage. If there is insufficient pressure difference between the system and storage, the condenser and boiler heaters are used to raise the isobutane system pressure above that of the storage tanks, thereby forcing fluid back to storage. Once the isobutane liquid operating levels are reached, the plant drain valves are closed and the plant is in a cold standby condition.

Plant Startup and Operation. The initial step in starting the plant from a standby condition is to check the operational status of all auxiliary systems and prepare both the geothermal fluid and cooling water systems for operation. The flare pilot is then ignited, if not already ignited from the system fill. Next, the cooling water system is started and flow is established through the condenser. At this point, the isobutane pumps are started and flow is established through the boiler bypass line (refer to Figure 1). The next step is to heat up the boiler and establish vapor flow from the boiler to the condenser. During this process, the turbine is isolated and the plant is operated as a thermal loop. Geothermal fluid is slowly introduced into the boiler. As the boiler pressure increases, the turbine bypass valve is adjusted to control the rate of increase (by increasing or decreasing vapor flow to the condenser). The boiler liquid level is maintained by feeding sufficient isobutane through the boiler inlet valve to offset the vapor flow discharging to the condenser. The geothermal fluid flow rate is increased slowly until boiler pressure and gas flow reach the desired operating levels.

When the system reaches steady state at desired boiler operating conditions in the thermal loop mode, the turbine outlet valve is opened and the inlet valve is opened slightly to allow a small amount of gas to flow through the turbine. This vapor flow warms the turbine and vaporizes any liquid that might be present in the turbine or turbine piping. Once the turbine is warmed up, the turbine inlet valve is slowly opened and the turbine bypass valve is closed, maintaining relatively constant vapor flow. As more vapor flow is diverted through the turbine, the speed of the turbine increases to an operating level, engages the clutch, and begins picking up the load, thus producing power. At this point, the turbine bypass valve is closed and the turbine inlet valve is fully opened. The boiler inlet valve and boiler bypass valve are then adjusted to stabilize heat exchanger liquid levels. The plant is now operating in the power loop mode. Unless the geothermal fluid flow is interrupted or some equipment malfunctions, the plant operation will be stable, with only periodic adjustments of heat exchanger liquid levels required.

Plant Shutdown. The normal procedure for a manual shutdown is to change plant operation from the power loop mode to the thermal loop mode. The geothermal fluid flow rate is then reduced at a rate slow enough that the operator can control pressures, flows, and heat exchanger 
levels until geothermal fluid flow is shut off. Isobutane flow is circulated through the loop, bypassing the boiler, until the boiler and condenser pressures are equal. At this point, the isobutane pumps are shut down, and heat exchanger levels allowed to equalize. The cooling water system is then shut down and, if another startup is not scheduled, all water systems are drained (except the fire protection system) and the flare pilot extinguished. The operator then makes the decision to put the plant in a full shutdown condition, i.e., isobutane drained back to storage, or to leave the plant in a standby mode.

Operating Limitations Encountered. The turbine unit is designed to operate at peak efficiency for an inlet pressure of $2.16 \mathrm{MPa}\left(104.4^{\circ} \mathrm{C}\right)$ and an exhaust pressure of $0.365 \mathrm{MPa}$. To produce the design turbine inlet conditions, it is necessary to increase the geothermal fluid flow rate and/or temperature to the boiler/preheater until the unit is operating at a high enough pressure to supply the desired turbine inlet conditions. In operation thus far it has not been possible to reach the geothermal fluid conditions $\left(0.0076 \mathrm{~m}^{3} / \mathrm{s}\right.$ at $138^{\circ} \mathrm{C}$ ) to produce design conditions at the turbine inlet. Although the plant operation has been at off-design conditions, it has been stable and reliable, and producing power at turbine inlet pressures ranging down to $1.24 \mathrm{MPa}$. It should be noted that, although design pressures were not achieved, essentially full flow and heat loads were achieved so that the system operated, in this sense, at design conditions.

The maximum inlet pressure attained was 2.12 $\mathrm{MPa}$, compared with the 2.16-MPa design value. The condenser pressure, however, never approached the design turbine exhaust pressure unless the turbine inlet pressure and flow were at considerably less than design values. For the design heat load, the condenser will operate at pressures between 0.483 and $0.724 \mathrm{MPa}$, depending on the ambient air temperatures. The $0.724-\mathrm{MPa}$ value is an upper operating limit imposed by (a) a maximum allowable turbine exhaust pressure of $0.862 \mathrm{MPa}$ and (b) the relief valve installed to protect the turbine. Cooling water circulates through the condenser at $0.0205 \mathrm{~m}^{3} / \mathrm{s}$, with a temperature rise of approximately $7.8^{\circ} \mathrm{C}$. The cooling water system is always operated at full capacity to achieve maximum cooling potential and power output.
The operating conditions for the plant are summarized in Table 2. The wide variation in conditions is primarily the result of availability of geothermal fluid and of a well to suppiy the experiment. During operation of the plant, geothermal fluid was supplied by one of three Raft River geothermal production wells (designated RRGE-1, RRGE-2, and RRGP-5), which supplied geothermal fluids at the approximate temperatures of 135,129 , and $124^{\circ} \mathrm{C}$, respectively. Which well was available was determined by the reservoir well testing that ran concurrently with the operation of the PPP.

\section{Operating Experience}

The PPP was completed in early April 1978, and the initial startup took place on April 27, 1978. Since resolution of the problems encountered during the checkout phase of testing, the plant operation has been stable and dependable when geothermal fluid was available. Additional information on the plant performance is included in a subsequent section titled "Performance Results." As would be expected, problems have been encountered in running the plant, some of which were unique to the plant and some of which might apply to other binary systems. The following discussions on plant operation will focus primarily on those experiences that might apply to the design or operation of other binary systems.

Diaphragm Feed Pump. As indicated in a subsection of the "Facility Description" section, the diaphragm feed pump originally installed in plant was eventually replaced with a centrifugal pump because of repeated diaphragm failure. Although considerable time was spent in attempting to discover the cause of the failure, no solution was reached that could provide a reasonable diaphragm life. The cause of the problem was suspected to be excessive differential pressure on the diaphragm during the suction stroke when the diaphragm was unsupported. Efforts to first reduce and then eliminate this differential pressure by pressurizing the feed pump crankcase were partially successful in that they extended the operating life of the diaphragm from 6 to $108 \mathrm{~h}$. This, however, was far short of the predicted operating life of over $2000 \mathrm{~h}$, and, consequently, the pump was replaced. 
Isobutane Working Fluid

Boiler pressure, $\mathrm{MPa}$

Boiler inlet temperature, ${ }^{\circ} \mathrm{C}$

Boiler outlet temperature, ${ }^{\circ} \mathrm{C}$

Turbine inlet pressure, $\mathrm{MPa}$

Turbine inlet temperature, ${ }^{\circ} \mathrm{C}$

Turbine outlet pressure, $\mathrm{MPa}$

Turbine outlet temperature, ${ }^{\circ} \mathrm{C}$

Condenser pressure, MPa

Condenser inlet temperature, ${ }^{\circ} \mathrm{C}$

Condenser oultlet temperature, ${ }^{\circ} \mathrm{C}$

Working fluid flow rate, $\mathrm{kg} / \mathrm{s}$ (maximum)
1.31 to 2.137

2.11 to 46.1

76.7 to 104.4

1.241 to 2.103

76.7 to 103.3

0.372 to 0.724

43.3 to 65.6

0.372 to 0.724

43.3 to 65.6

21.1 to 46.1

1.6506

Geothermal Fluid

Flow rate, $\mathrm{m}^{3} / \mathrm{s}$

0.0032 to 0.0073

Inlet temperature, ${ }^{\circ} \mathrm{C}$

118.3 to 137.8

Outlet temperature, ${ }^{\circ} \mathrm{C}$

87.8 to 110

Cooling Water

Flow rate, $\mathrm{m}^{3} / \mathrm{s}$

0.0189 to 0.0221

Inlet temperature, ${ }^{\circ} \mathrm{C}$

11.7 to 26.7

Outlet temperature, ${ }^{\circ} \mathrm{C}$

15 to 33.3

Although the diaphragm feed pump did not provide the anticipated operating life, there were many aspects of it and its incorporation into the turbine skid that made it preferable to the centrifugal pump that replaced it. In the original arrangement of the Barber-Nichols turbine skid (see the "Facility Description" section for discussion of the skid), the boost pump and the diaphragm feed pump shared a common driver; the turbine in power loop operation or induction motor/generator in thermal loop operation. This configuration minimized the costs that would be associated with providing separate drivers (motors) for each pump and eliminated the parasitic power losses that would be associated with having multiple pump drivers. The pumps, however, did have parasitic power losses in the gearboxes and belt drives (required to run from the interconnecting shaft between the turbine and motor/generator) that might not have been present if separate pump drivers were used.

Although the plant power output, as indicated by motor/generator power reading, increased significantly when the diaphragm pump was replaced by the centrifugal pump, this power increase was due solely to the removal of the diaphragm pump load from the shaft between the turbine and motor (the centrifugal pump had its own driver). In actuality, the performance of the diaphragm pump, in terms of efficiency, was considerably better than that of the centrifugal pump ( $75 \%$ as opposed to $41 \%$ ); thus, for a given set of turbine conditions, the net plant power output was higher prior to replacement of the diaphragm pump.

The operating characteristics of the diaphragm pump were preferred to those of the centrifugal pump in operating the PPP. The diaphragm pump provided a relatively constant flow rate regardless of pump head. This characteristic enabled the plant to be started at a low boiler pressure. The control valve positions were then established and the system (boiler) pressure increased by increasing geothermal flow rate, with little adjustment of control valve positions required. The constant flow characteristic of the diaphragm pump also enabled the plant to react to gradual or sudden (within some limitations) changes in geothermal 
fluid conditions without automatically shutting down. In contrast, the variable-head-flow characteristic of the centrifugal pump required a specific valve position (boiler inlet) for a given system pressure to keep from starving or flooding the boiler with working fluid. This characteristic of the centrifugal pump made plant startup more difficult and made plant operation sensitive to changes in the geothermal fluid, which, at times, resulted in an automatic shutdown.

Winter Operation. Operation of the PPP in subfreezing temperatures poses a number of operational problems that require closer monitoring of the plant. Many of these problems would likely occur with any binary system located outside in areas where cold ambient conditions exist,and should be considered in the design of the facility. The major problems encountered in operating the plant are

1. Power outages/vacuum hazard

2. Plant fill and drainback to operating levels
3. Freezing of water and instrument air lines

4. Cooling tower icing.

Power outages pose several operational problems during winter operation. The obvious problem is the potential freezing of piping, heat exchangers, pumps, instruments, etc., that contain water. A more serious problem is the potential for a vacuum (or explosive) hazard that exists as the air temperature falls. The problem may become more clear if one considers the saturation pressure versus temperature curve in Figure 7.

When the plant is shit down at nominal heat exchanger levels, the system pressure corresponds to the saturation pressure of isobutane at the temperature of the plant (which is usually equivalent to the ambient air temperature). If the plant is shut down when air temperatures are low, then the system pressure will be low (see Figure 7). In general, the minimum system pressure maintained in the PPP is $0.154 \mathrm{MPa}$ shich corresponds to an air temperature of approximately

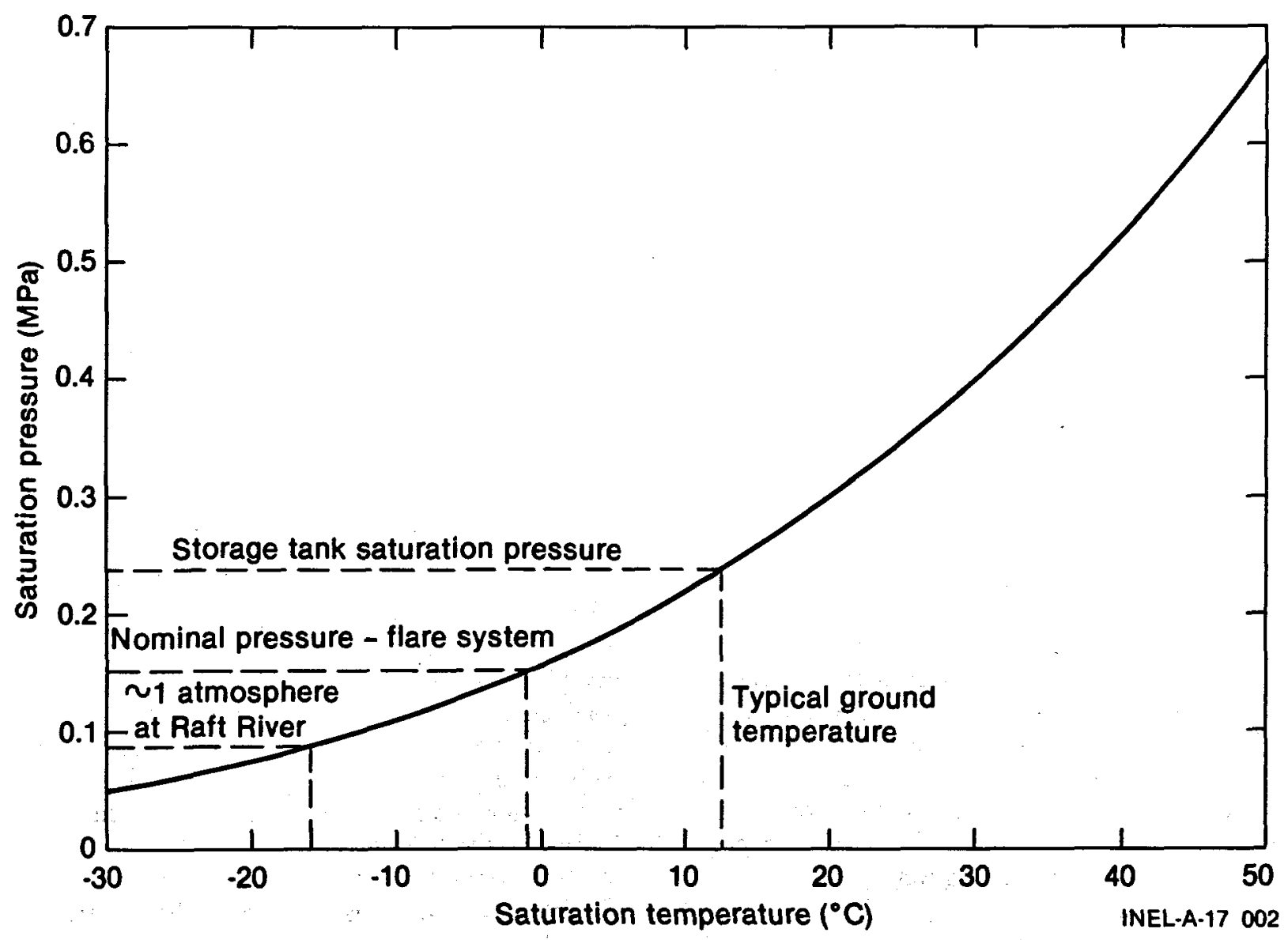

Figure 7. Isobutane saturated temperature-pressure curve. 
$-1.1^{\circ} \mathrm{C}$ or higher. If the air temperature falls below $-1.1^{\circ} \mathrm{C}$, or if a higher system pressure is desired, strip heaters wrapped around the heat exchanger units (under the insulation) normally provide an external heat source to raise the fluid temperature and maintain the minimum system pressure. In the event of a power outage, these strip heaters are inoperative and if the air temperature is sufficiently low $\left(\sim-16^{\circ} \mathrm{C}\right)$, the isobutane system may draw a vacuum and air may enter the system, creating a potential explosive hazard. Although this is not a problem at some geothermal locations such as the Imperial Valley of California, it is a very real problem at Raft River where subzero temperatures are not uncommon and subfreezing temperatures are daily occurrences during the winter. If the plant shows the potential for a vacuum hazard, the operator puts the system under a positive nitrogen pressure blanket (if external surface heaters are inoperative due to power outage). Nitrogen is introduced only as a last resort, because the plant must then be liquid filled, noncondensables vented, and drained back to operating levels before it can be operated.

The filling and drainback of the isobutane system during the winter is extremely difficult to monitor using the existing plant instrumentation. When filling the plant, the operator relies on the flashing of the isobutane as it enters the flare system (nominally $0.154 \mathrm{MPa}$ ) to determine whether the system is liquid full. If the system is liquid full, the liquid isobutane will flash across the vent valve and the reading on the temperature indicator on the flare side of the valve will fall to approximately $-1.1^{\circ} \mathrm{C}$ (saturation temperature at $0.154 \mathrm{MPa}$ ). If the system temperature is below $-1.1^{\circ} \mathrm{C}$, the isobutane liquid does not flash when going through the venting valve and the operator cannot tell when the system is liquid full. This characteristic of the plant limits the filling procedure to periods of day when temperatures are above freezing (which may not occur during some winter days). Problems are also encountered in drainback to operating levels, because the plant is often at a lower pressure and temperature than the buried storage tank. This problem is generally resolved by using surface heaters on the boiler/preheater and condenser to raise system pressure above that of the storage tank.

As previously discussed, the initial operator action following a shutdown in the winter is the draining of water from systems, components, and instruments. The potential for freezing damage also exists when the plant is running. Instruments and lines to instruments that sense water pressure but have no flow were heat taped and insulated to prevent freezing. If these instruments froze, the operator would receive an erroneous reading and alarms. A more serious problem would occur if moisture in the instrument air system condensed and froze. The loss or blockage of instrument air supply or signal would cause the control valve to "freeze" in a given position or fully open or close, upsetting the plant and causing an automatic shutdown.

The most frequent problem encountered during winter operation of the plant was icing in the cooling tower. During the winter, one end of the tower was shaded except for possibly 1 or $2 \mathrm{~h}$ each day. As a result, ice would start to form on the tower structure and the fill in the shaded end whenever the air temperature reached $0^{\circ} \mathrm{C}$. No ice would form in the end of the tower not in the shade until the air temperature fell below $-1.1^{\circ} \mathrm{C}$. By the time the air temperature reached about $-4^{\circ} \mathrm{C}$, approximately 30 to $40 \%$ of the area in the shaded end would be blocked with ice, and slats in the tower fill would fall out. The end of the tower not in the shade would have 15 to $25 \%$ blockage at the same temperature.

Icing in the cooling tower was controlled by periodically reversing the cooling tower fan direction. Once the ice that had formed on the ends of the tower had melted, the fan direction was changed back to the normal operating status (i.e., drawing air in the ends of the tower). At ambient air temperatures of $-4^{\circ} \mathrm{C}$, the tower fan direction was reversed for approximately $30 \mathrm{~min}$ every 6 to $8 \mathrm{~h}$. When the air temperature dropped below $-7^{\circ} \mathrm{C}$, the fans were reversed every 4 to $6 \mathrm{~h}$, and when the air temperature fell below $-12^{\circ} \mathrm{C}$, the fans were reversed every 2 to $4 \mathrm{~h}$. In addition to protecting the cooling tower from damage, the fans were reversed to keep cooling water temperatures low (thus, condenser pressure would be low and power output high).

"Sun" Boiling in Isobutane Piping. Plant startups made during the warmer part of summer days would sometimes fail because the isobutane pumps would not develop any head or flow due to insufficient pump net positive suction head. When the plant is in a standby condition at operating liquid levels, the system pressure is maintained at the saturation pressure corresponding to the surrounding air temperature (except during the 
winter when the condenser and boiler heaters are turned on to maintain a positive system pressure). In starting the plant from a standby condition, one of the initial steps is to establish cooling water flow through the condenser. If the water is cooler than the ambient air temperature, the isobutane temperature and pressure in the condenser decrease, which decreases the pressure in all the liquid isobutane piping in the plant. The liquid in the uninsulated piping, however, is at a higher than saturation temperature and it begins to boil; thus, the pumps do not have sufficient NPSH for starting.

The required NPSH for the PPP working fluid boost pump is $0.91 \mathrm{~m}$ of head, and the head available is approximately 1.52 to $1.82 \mathrm{~m}$. If the process system is at $27^{\circ} \mathrm{C}$, a condenser temperature decrease of approximately $1.0^{\circ} \mathrm{C}$ would initiate the boiling of the isobutane working fluid at the boost pump suction (assuming the pump fluid remains at $27^{\circ} \mathrm{C}$ ). The problem was resolved by starting the isobutane pumps prior to starting the cooling water flow. This, for the most part, eliminated the startup difficulties, although there were instances in which the plant would not start because of naturally occurring temperature differences between the condenser and the process piping. In these instances, startup could be achieved by using the condenser and boiler heaters to increase condenser temperature and pressure.

This problem is not unique to the plant and can occur in any similar process facility in which the design and procedures do not account for the possibility of temperature differences between the condenser and feed or boost pump suction. It should be noted that this problem may not be unique just to the solar heating of the liquid working fluid in the process piping, but can occur any time the condenser pressure is suddenly decreased without a corresponding decrease in fluid temperature.

Working Fluid Losses. The initial test runs with the plant were generally short (less than $24 \mathrm{~h}$ ) because of the feed pump diaphragm failures. Because these runs were relatively short and because of the operational problems encountered during these runs, it was not possible to obtain any significant amount of repeatable data on the amount of working fluid lost during normal operation of the plant. Once the feed pump was replaced and the plant had operated for periods of several days without shutdown, it was apparent that the plant was losing significant amounts of working fluid. The plant isobutane system piping was checked with a hydrocarbon detector to find the source of the leakage. These examinations did not reveal any major isobutane leak; however, they indicated that almost all mechanical joints and seals in the plant leaked isobutane to some degree and that the daily loss of isobutane observed was the summation of all the small leaks. The average daily loss of isobutane was approximately 11.3 to $13.6 \mathrm{~kg}\left(\sim 0.026 \mathrm{~m}^{3}\right)$ per day.

The mechanical joints and pump seals were periodically checked with the hydrocarbon detector for points of leakage. Flanged joints in the plant were a raised-face type, using Flexitallic gaskets of the appropriate pressure rating. The packing material for the manual valve in the plant was generally a braided asbestos type with a graphite-impregnated core (John Crane 187-1 or equivalent) suitable for air, water, steam, and liquid petroleum service. The control valves in the plant had a teflon asbestos packing material.' If excessive leaking was noted when the joints were checked, the flanged joints were retorqued and valve packings adjusted (tightened slightly). In general, however, it was not possible to completely seal the various joints, and isobutane had to be added to the plant on a daily basis while it was operating to make up the average daily loss noted previously.

Noncondensable Gases. Following replacement of the diaphragm pump, the plant entered a period of long-term, continuous operation, i.e., auto-run test phase. After approximately 35 days of operation, the plant power output began to decrease significantly (30\% decrease by day 40$)$, even though the geothermal fluid and cooling water temperatures and flow rates remained relatively constant. During this period of approximately one week, the condenser pressure increased by approximately $0.07 \mathrm{MPa}$, and it was suspected that the cooling water side of the condenser heat exchanger tube had fouled. However, treatment of the cooling water and chemically cleaning the condenser tubes for potential fouling did not significantly increase condenser performance (reduce condenser pressure) or improve the plant power output.

When the chemical cleaning of the cooling system (i.e., condenser) did not improve plant performance, contamination of the isobutane system with noncondensable gases, specifically 
nitrogen, was suspected. Contamination of isobutane with nitrogen had been previously considered; however, the degradation in plant performance had been rapid when compared to the total time the isobutane had been exposed to the nitrogen (1 week as opposed to 18 months). The exposure of working fluid to the nitrogen up until the time of the auto-run test phase, however, had been limited, in that the partial pressure of the nitrogen blanket on the plant and/or storage was generally about $0.035 \mathrm{MPa}$. This nitrogen partial pressure would increase during the process system fill; however, it would be vented to the flare system during drainback to operating levels. When the plant went into the long-term, continuous operation test phase, isobutane had to be added daily to replenish working fluid losses in the plant due to leakage. In order to add this fluid without shutting down the plant, it was necessary to pressurize the storage tank to values 0.035 to $0.069 \mathrm{MPa}$ in excess of the condenser pressure so that fluid could be added to the condenser with the plant running. To conserve time and nitrogen when recharging the plant isobutane inventory, the storage tank was left pressurized at or slightly above condenser pressure. It was suspected that this excess nitrogen pressure in the storage had forced the nitrogen into solution in the isobutane used as makeup to the plant. When this isobutane was added to the process system, the nitrogen came out of solution in the boiler (as the liquid vaporized) and accumulated in the condenser until the partial pressure of the nitrogen in the condenser and the amount of nitrogen in the liquid leaving the condenser reached an equilibrium condition. The daily addition of isobutane from storage upset this steady state condition by supplying a regular source of nitrogen, thus forcing the partial pressure of the nitrogen and the total pressure in the condenser higher, which in turn dropped the power output level with time.

To verify the existence of excessive amounts of nitrogen in the system, samples were taken at various points in the isobutane process loop. Care was taken to ensure that each sample was twophase, i.e., liquid and vapor. The samples were then placed in a constant temperature bath and pressure measurements were made, which were compared to isobutane properties, i.e., saturation pressure at the sample temperature. These samples indicated that nitrogen was present in the plant isobutane system. A fluid sample was sent to the isobutane supplier who confirmed that nitrogen was present in quantities necessary to add approximately $0.07 \mathrm{MPa}$ to the condenser pressure.
Upon determination that nitrogen was present in the isobutane system, the plant was shut down and the entire inventory of isobutane was vented to the flare system and burned. The plant and storage tank were then filled with fresh isobutane without using any nitrogen. When the plant was started up again, the power output was $60 \%$ higher than it was before any plant performance degradation was observed, even though the geothermal fluid was at a lower flow rate and was slightly cooler. The temperature differences between the cooling water inlet or outlet stream and the isobutane saturation temperature corresponding to measured condenser pressure also returned to previous levels.

Since the isobutane was replaced, the use of nitrogen has been minimized. Nitrogen is still required to pressurize the working fluid to make up for losses; however, after filling, all excess pressure in the storage tank is vented to the flare. As long as nitrogen is used to move the fluid into and out of storage and to maintain a minimum system pressure, some contamination of the isobutane will occur.

Turbine. Following completion of the system performance tests in December 1979, the plant was not operated for approximately one month due to the cold weather and reduced operation support during the Christmas holidays. Initial attempts to start the plant following this period were unsuccessful because of a low turbine skid oil pressure. Several startup attempts were required to bring the working fluid feed system on-line, and then it was determined that the oil pressure was low and erratic. After determining that the problem was internal to the turbine gearbox, the assembly was removed and sent to Barber-Nichols for repair. The cause of the low oil pressure was found to be excessive wear and/or clearance in the oil pump drive off the low-speed (3600 rpm) shaft in the gearbox. This problem was corrected by Barber-Nichols and the assembly returned.

While the turbine gearbox assembly was at Barber-Nichols, the turbine assembly was dismantled and inspected. This inspection revealed a small piece of metal (see Figure 8) lodged in the turbine wheel blading. This piece of debris appeared to be weld slag that had not been removed in the system flush during the initial plant construction. Although this debris caused some erosion of the turbine nozzle (see Figure 9) and unbalanced the turbine wheel, no significant degradation of the turbine performance was noted 


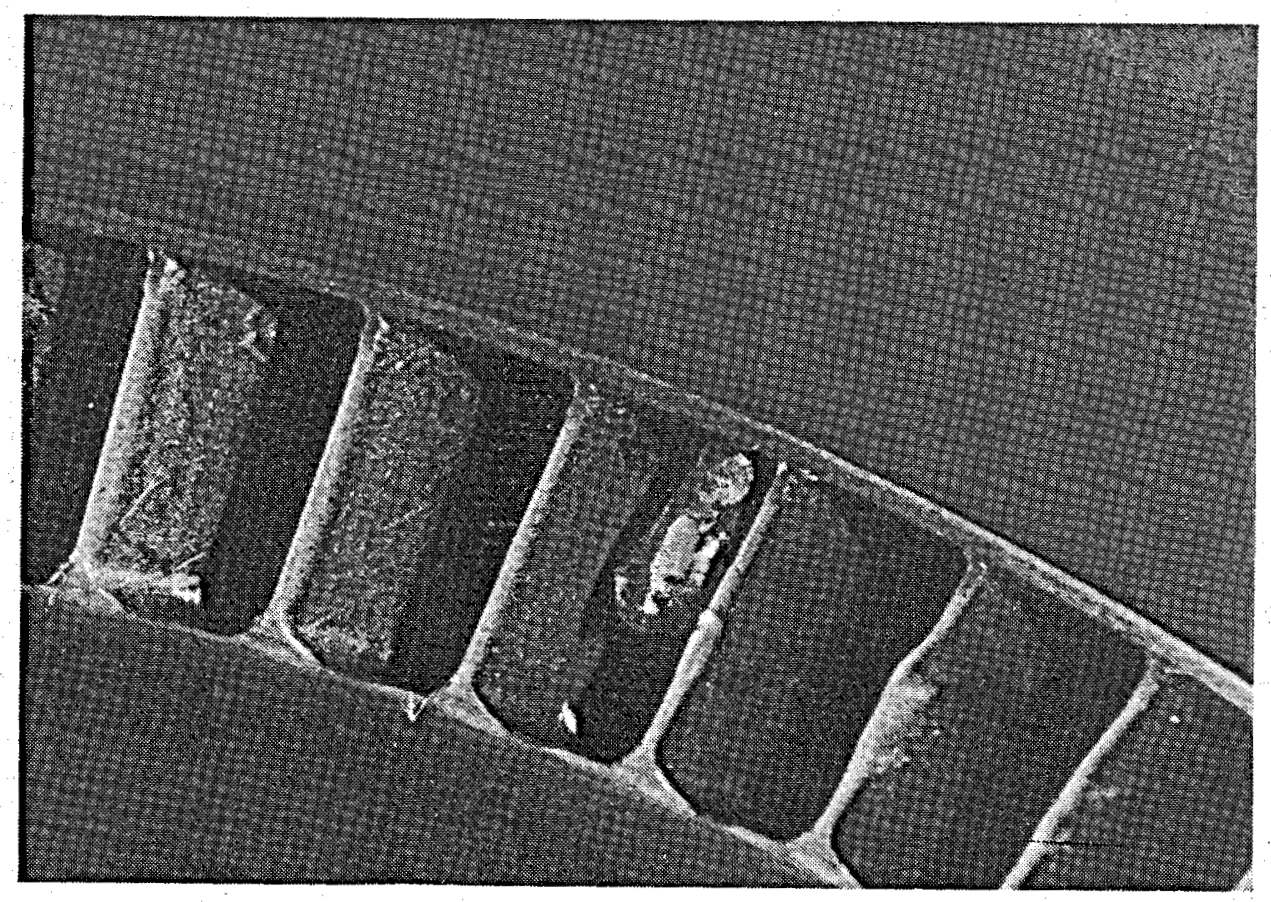

Figure 8. Debris in prototype turbine wheel.

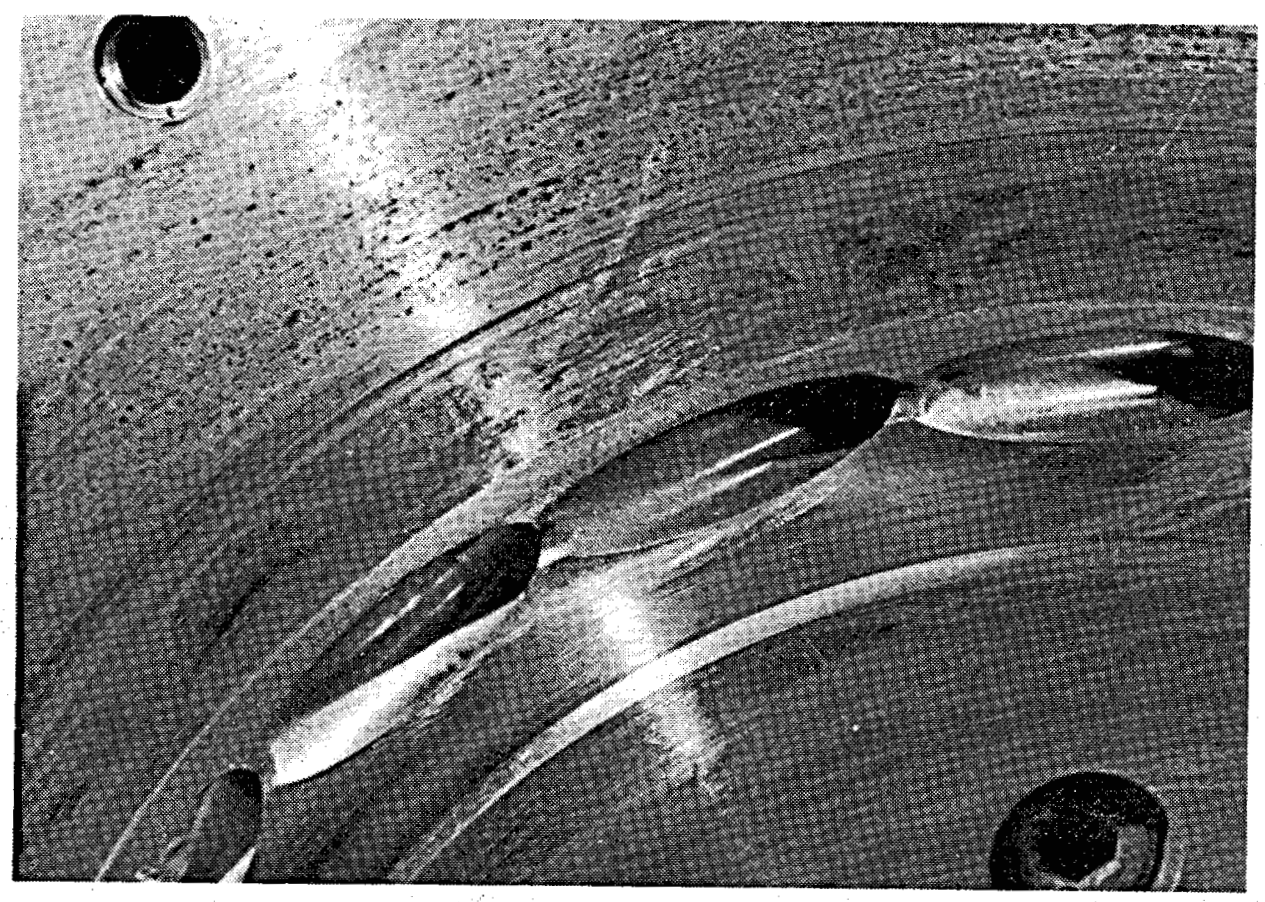

Figure 9. Erosion of prototype turbine nozzles. 
by Barber-Nichols 1 or the Idaho National Engineering Laboratory in reviewing the test data.

\section{Auto-Run Test Modifications}

The prototype plant was initially designed for operation with a minimum of one operator present to monitor the plant, adjust valves, record data, etc. Some automatic control (boiler level and pressure) was built into the plant initially. During the test runs with the diaphragm feed pump, the control was changed so that the condenser level was automatically controlled instead of the boiler level. This change was made to ensure the necessary net positive suction head for the isobutane boost pump.

In a binary power plant design, the condenser usually discharges into a hot well or condensate storage vessel, the level of which supplies the required NPSH to the recirculating boost and/or feed pumps. Because the inventory of fluid in the hot well is relatively large, changes in level are slow and the plants are generally controlled on the boiler level to provide constant turbine inlet conditions. In the PPP, however, there is no hot well and it is necessary to maintain a certain level in the condenser unit to provide the required boost pump NPSH. Because the cross-sectional area on the shell side of the condenser is small, the level changes rapidly if the flow into or out of the condenser changes. The level is also sensitive to temperature changes in the liquid isobutane portion of the plant cycle (density changes) and to the loss of working fluid through various joints and seals in the plant (daily losses lowered condenser level by as much as $25.4 \mathrm{~cm}$ ). The sensitivity of the condenser level and the desire to maximize condenser performance (the higher the liquid level, the more heat exchange surface area covered and not available for condensing heat load) necessitated the change of control from boiler level to condenser level. This control of liquid level was achieved through the automatic adjustment of the boiler bypass control valve position, which had the effect of varying the flow of working fluid into the boiler.

The plant was also designed to maintain a constant boiler pressure through control of the geothermal fluid flow rate. The geothermal fluid discharge valve controller sensed boiler pressure and adjusted the valve position as required to maintain pressure. In general, this control mode was not used because of low geothermal fluid flow rates and temperatures and the desire to maximize power output.

The PPP was originally designed with some automatic shutdown logic, but except for the high boiler pressure shutdown, all shutdown logic was associated with protecting the turbine. In addition, alarms annunciated in the event of upset conditions in either the boiler or condenser. The test runs made during plant checkout, i.e., the diaphragm feed pump checkout, showed that the plant operation was stable when controlling the condenser level automatically with the boiler bypass valve. Although the operation of the plant was stable, an operator was still required to monitor the plant condition and shut the plant down if necessary. During the latter stage of the system checkout test phase, the decision was made to modify the plant shutdown and alarm system so that the plant could be left operating unattended. In the event of any upset condition, an alarm would enunciate, and if no corrective action was taken, the plant would shut down automatically. The alarm and shutdown modes for the plant after this modification are listed in Table 3.

If one of the alarms initiated an automatic emergency shutdown, it would occur in a manner that would minimize any potential hazards. In an automatic shutdown, the working fluid pumps and the geothermal fluid supply are shut off. The turbine inlet valve also closes, shutting off vapor flow through the turbine. If the plant was operating as a power loop, then the turbine bypass valve would be closed, and the boiler would be isolated from the condenser and the turbine, except for backflow from the bottom of the boiler through the boiler bypass valve to the condenser. This bypass valve would eventually close on a high condenser level signal to the controller. The cooling water flow would be maintained during the shutdown to cool the condenser and reject the heat from any backflow from the boiler/preheater. An initial concern was the possibility of isolating and overpressurizing the boiler during shutdown. A boiler pressure spike was noted immediately after some of the automatic shutdowns; however, these increases in pressure were generally less than $0.172 \mathrm{MPa}$, and had decayed back to the original pressure within $3 \mathrm{~min}$ after shutdown. Generally, the boiler pressure (with the boiler isolated) would decay to less than $0.689 \mathrm{MPa}$ within about $2 \mathrm{~h}$ following a shutdown (this could be accomplished in less than an hour if excess boiler pressure was vented to the condenser). 


\section{Table 3. Prototype Power Plant alarm and shutdown modes, automatic-run modification}

\begin{tabular}{ll}
\hline Alarm & Parameters \\
1. & Flare pilot out \\
2. Flare blowdown imminent \\
3. Turbine exhaust high pressure \\
4. Boiler high pressure \\
5. Condenser low level \\
6. Condenser high level \\
7. Boiler low level \\
8. Boiler high level \\
9. Low isobutane boiler feed flow \\
10. Low power output \\
11. Low cooling water flow \\
12. Low cooling tower makeup water flow \\
13. Low geothermal fluid flow \\
14. Flashing in geothermal fluid piping \\
15. Feed pump diaphragm failure \\
16. Low feed pump suction pressure \\
17. Low air pressure \\
18. Low nitrogen pressure \\
19. Low flare system pressure \\
20. Low system pressure (vacuum hazard)
\end{tabular}

Shutdown Parameters

1. Turbine oil low pressure

2. Turbine oil high temperature

3. Turbine vent high pressure

4. Turbine overspeed

5. Boost pump failure

6. Low isobutane feed flow

7. Turbine exhaust high pressure

8. Loss of electrical power

9. Flare pilot out

10. Boiler high pressure

The performance of the plant following the auto-run modifications is summarized in the following section-"Performance Results." During the 5-month period that the plant operated in the auto-run test phase, it experienced several automatic shutdowns, which occurred exactly as intended. The major causes of the automatic shutdowns during this phase of testing were the loss of site electrical power and dips in line voltage that would trip some of the alarms and trigger an automatic shutdown. These shutdowns, particularly those due to line voltage fluctuations, are unique to the PPP and would not be expected to cause similar problems in a commercial-size power plant.
The auto-run modifications were intended to provide the alarm and shutdown modes that would allow the plant to operate unattended. Prior to these modifications, a minimum of one operator was required when the plant was running. Following the modifications, the operator manpower requirements were reduced to less than $8 \mathrm{~h}$ per day, most of which were required for data collection and recharging the process system with isobutane.

\section{Operation Summary and Conclusions}

The operating experience thus far with the PPP can be summarized as follows:

1. Limitations of the condenser and lack of adequate temperature geothermal fluid has prevented the plant from operating in the power loop mode at design turbine inlet and exhaust conditions.

2. The diaphragm feed pump originally installed in the plant had to be replaced because of repeated diaphragm failure. Although the pump did not have the desired operating life, it had many operating characteristics that made it preferable to the centrifugal pump that replaced it. From an operational standpoint, a reliable and efficient positive displacement pump should be considered for any small binary system.

3. The Barber-Nichols turbine skid components (aside from diaphragm pump) operated reliably and with minimal operational problems. Although debris was found in the turbine wheel blading, no significant degradation in turbine performance was noted. The design and construction of the skid minimized installation costs and simplified the operation of the plant. This type of arrangement should also be considered in the design of small binary systems.

4. Cold weather operation of the plant requires that a binary system be designed to handle the potential for vacuum (explosive) hazards in the isobutane system, and that additional consideration be given to the process system fill and draining in subfreezing temperatures. 
5. Temperature differences between the condenser and working fluid recirculating pumps can cause startup problems, particularly during warm summer days.

6. As would be expected, the mechanical joints and seals in the plant were not $100 \%$

4. effective in preventing isobutane leakage. This leakage was minimized through regular adjustment of packing and retorquing of flanged joints; however, while the plant was running, fluid had to be added daily. The leakage was worse while operating than when not, and when operating at higher boiler pressures.

7. Nitrogen will dissolve into an isobutane working fluid and unless the use of nitrogen is minimized, the working fluid will become contaminated and plant performance adversely affected. The potential for nitrogen contamination and degradation is common to all binary plants using nitrogen as a purge gas and as a means of maintaining positive system pressures. Noncondensable gas contamination should be considered in designing direct contact plants using a geothermal fluid that contains nitrogen, since some means must be available to remove the noncondensable gas from the condenser and minimize the degradation in condenser performance.

8. The automatic-run modifications to the PPP operated as intended, shutting the plant down automatically in the event of upset conditions. This feature enabled the plant to be operated continuously with minimal operator surveillance. The modification reduced operator manpower requirements from $24 \mathrm{~h}$ to less than $8 \mathrm{~h}$ per day, most of which was required for data collection and recharging the isobutane system. 


\section{PERFORMANCE RESULTS}

\section{Plant Performance - Auto-Run Test Phase}

During the period between the initial startup and the replacement of the diaphragm feed pump, the Prototype Power Plant operated as a power loop for $172 \mathrm{~h}$, producing a total of $4575 \mathrm{~kW} / \mathrm{h}$, or an average of $26.6 \mathrm{~kW}(\mathrm{e})$. The period of operation with the diaphragm feed pump was primarily devoted to resolving problems associated with the pump and completing the shakedown and checkout of the plant, and not with maximizing power output or operating for extended periods. As such, the plant operating factor during this period is not considered a fair assessment of plant performance. The plant operating factor is defined here as the ratio of the actual operating time to the time available for plant operation.

After the modification for automatic operation and the subsequent replacement of the diaphragm feed pump, the plant entered a test series during which it was to be operated with minimal operator surveillance for extended periods to obtain operational time on the plant and its components. This sequence of runs started in August 1979 and continued through December 1979 whenever geothermal fluid was available for operation. This period of operation is summarized in Table 4.

During the auto-run test phase, the operational time accrued in the months of September, October, and November was at considerably less than design geothermal fluid temperature and flow; thus, the power output during this period was low. The sources of geothermal fluid over this period were from Wells RRGE-2 and RRGP-5, neither of which can supply sufficient flow and temperature to approach design boiler conditions. Over this three-month period, geothermal fluid temperature and flow varied between 123.9 to $129.4^{\circ} \mathrm{C}$ and 0.0032 to $0.0047 \mathrm{~m}^{3} / \mathrm{s}$. Because the geothermal fluid supply was not sufficient (either in flow or temperature), the design isobutane turbine inlet pressure and vapor flow rate were not achieved. The only system operating at design flow conditions during this period was the cooling water. This was also the period when the isobutane became contaminated with nitrogen; therefore, condenser performance was not as expected. Although the plant did not operate con- tinuously at design conditions, it did have a planit operating factor of approximately $87 \%$. In defining the plant operating factor, the total number of hours available for operation was derived as the total number of hours minus those periods in which the plant could not operate because no geothermal fluid was available, the operation interfered with other site activities (work, tests, etc.), and/or trained operators were not present. Although the plant would run essentially unattended, operators were required to start up the plant following a shutdown or prepare it for a standby condition. If these personnel were not available, the plant was not operated in order to minimize the possibility of damage (particularly in the winter to prevent freezing damage).

\section{Floating Power Results}

"Floating power" refers to the variations in plant power output due to daily and seasonal variations in the ambient air temperature. During the auto-run test phase, the plant cooling water system was operated at a fixed flow rate; therefore, for fixed geothermal fluid conditions (i.e., heat input), the condenser pressure varied directly and the power output generally varied inversely with the ambient air conditions. The maximum levels of power output were expected to occur at night and during the winter when air temperatures were lower and the greatest potential for cooling existed. The data shown in Figures 10 and 11 are examples of the daily power cycles in the summer and winter. The maximum daily variation in power output was approximately $33 \%$, and if one compares the maximum, winter power output with the minimum summer power output, there is about a $79 \%$ change due to seasonal ambient variations.

The data in the two figures show that the daily power variations are considerably more significant in the summer than in the winter. This is due in part to larger changes in the ambient air temperature in the summer than in the winter. However, the smaller daily changes in the air temperature do not completely explain the smaller variations in power in the winter. Since this is the period of maximum power output for plants utilizing the concept of "floating power," the design and economic analysis of these plants 
August 1979

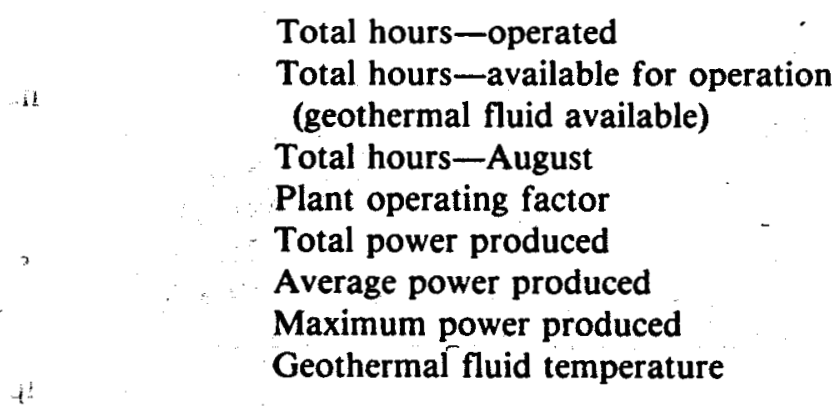

$$
\begin{aligned}
& 331 \\
& 378 \\
& 74 \\
& 744 \\
& 87.6 \% \\
& 9090 \mathrm{kWh} \\
& 27.5 \mathrm{~kW} \\
& 45 \mathrm{~kW} \\
& 138^{\circ} \mathrm{C}
\end{aligned}
$$

September 1979

Total hours-operated

Total hours-available for operation

142

Total hours-September

142

Plant operating factor

Total power produced

Average power produced

Maximum power produced

Geothermal fluid temperature

720

$100 \%$

$2115 \mathrm{kWh}$

$14.9 \mathrm{~kW}$

$24 \mathrm{~kW}$

$124^{\circ} \mathrm{C}$

October 1979

Total hours-operated

Total hours-available for operation

662

Total hours-October

Plant operating factor

Total power produced

Average power produced

Maximum power produced

$7067 \mathrm{kWh}$

$13.3 \mathrm{~kW}$

Geothermal fluid temperature

$27 \mathrm{~kW}$

$129^{\circ} \mathrm{C}$

November 1979

Total hours-operated

Total hours available for operation

Total hours-November

Plant operating factor

Total power produced

Average power produced

Maximum power produced

Geothermal fluid temperature

201

720

$93.5 \%$

$4043 \mathrm{kWh}$

$21.5 \mathrm{~kW}$

$32 \mathrm{~kW}$

$129.4^{\circ} \mathrm{C}$

December 1979

Total hours-operated

Total hours - available for operation

Total hours-December

Plant operating factor

744

Total power produced

$95.4 \%$

Average power produced

$6876 \mathrm{~kW}$

Maximum power produced

$41.4 \mathrm{~kW}$

Geothermal fluid temperature 
Table 4. (continued)

Summary

Total hours-operated

Total hours-available for operation

Plant operating factor

$87.2 \%$

Total power produced

$29191 \mathrm{kWh}$

Average power produced

$21.5 \mathrm{~kW}$

Maximum power produced

$59 \mathrm{~kW}$

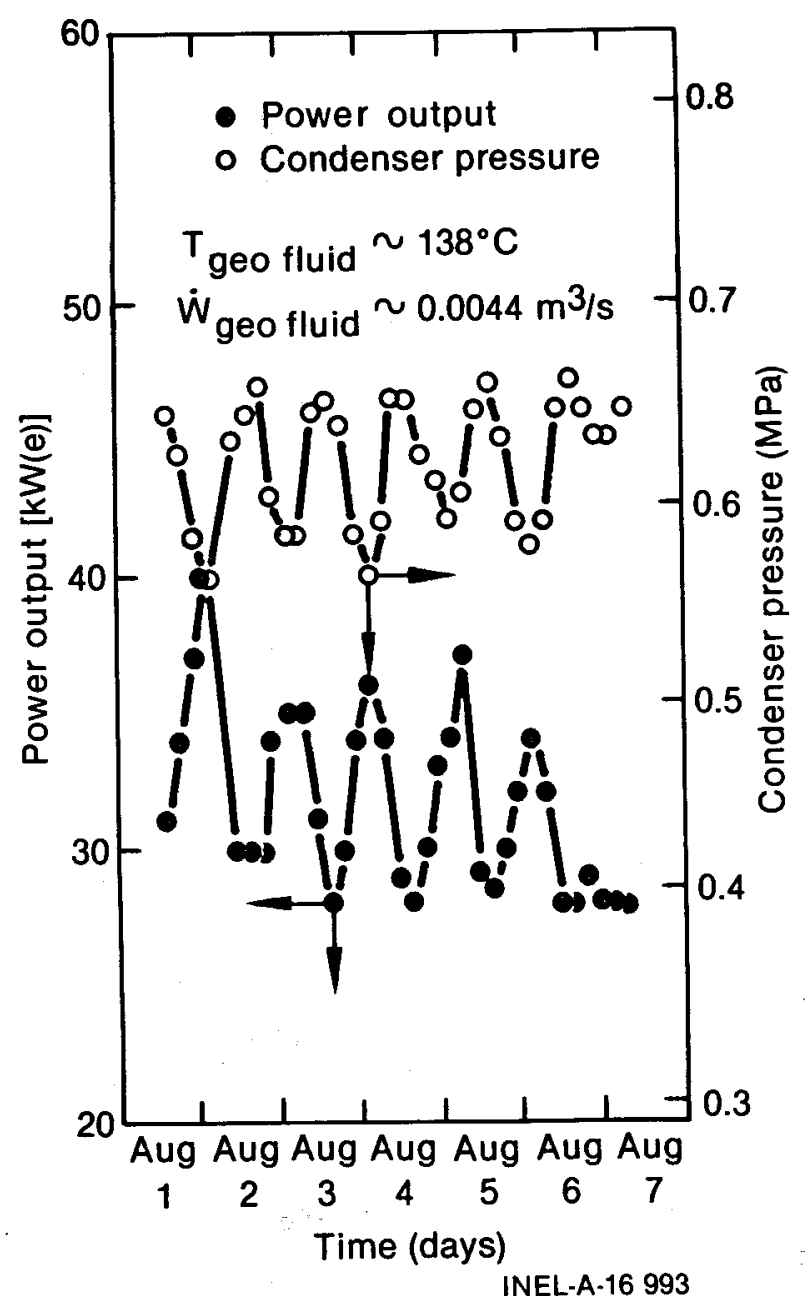

Figure 10. Daily power variations during summer, August 1979.

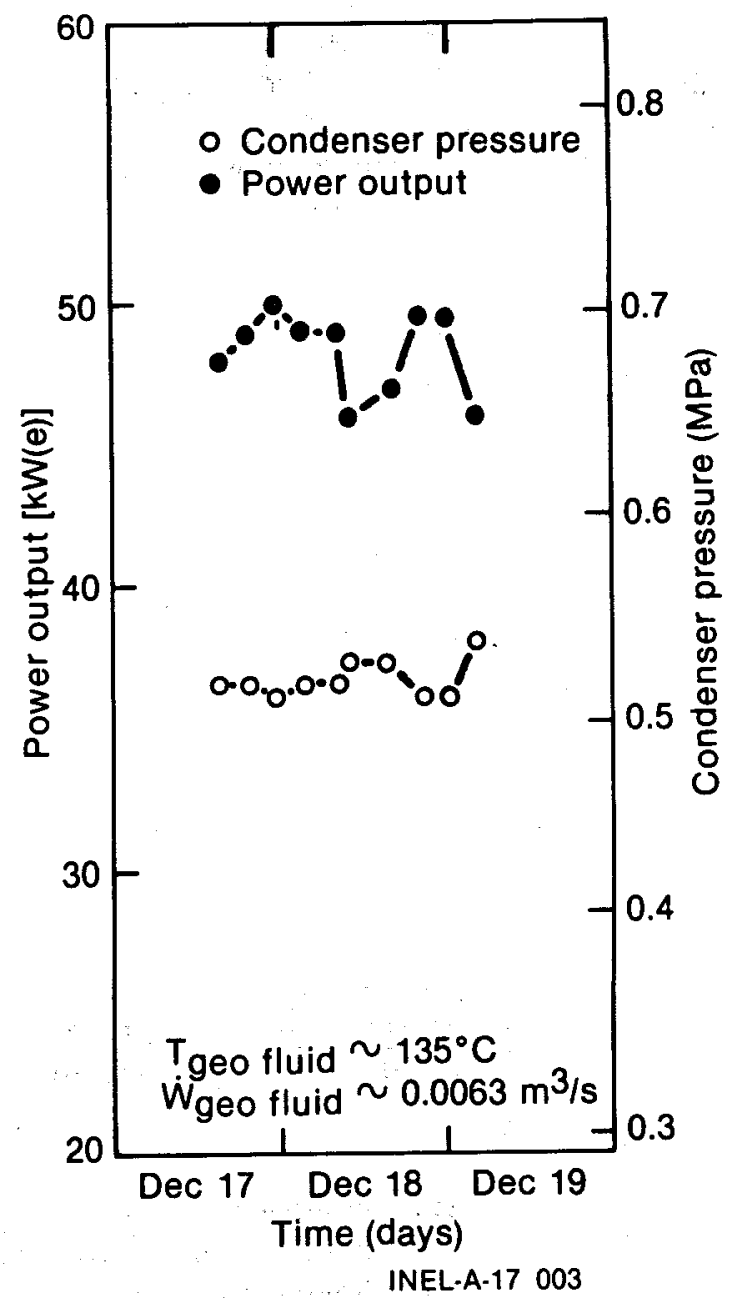

Figure 11. Daily power variations during winter, December 1979. 
should consider those factors that might influence output during these periods of maximum production.

As indicated previously, ice began forming in the PPP cooling tower when the ambient air temperature reached freezing $\left(0^{\circ} \mathrm{C}\right)$. As the air temperature decreased, ice would continue to form until significant blockage of the air flow area occurred. The reduction of this flow area would reduce the air flow through the tower fill as well as the effective area for heat and/or mass transfer between the air and cooling water. An example of the effect of icing on the cooling tower perform. ance is given in Figure 12, which shows actual performance data as well as the anticipated performance based on predictions provided by the - tower vendor, Marley Cooling Tower Co. The immediate observation from these data is that the tower does not operate as well as predicted at any point over this operating range. There are several possible explanations: error in the wet bulb temperature measurement; incorrect installation of tower fill and deteriorated tower condition; predictions based on different air conditions, elevation, etc.; and vendor overestimation of tower performance. It is probable that the difference between actual and predicted performance is due to a combination of these.

The shaded area in Figure 12 is the author's fairing through the test data. The dashed line through the data is parallel to the anticipated performance and represents the offset or difference between actual and predicted performance. This line is intended to show the deviation in tower performance as the ambient temperature approaches and drops below freezing. The offset of this dashed line from expected performance is also an author's fairing, and its location can change the point at which icing begins to affect tower performance. As mentioned previously, however, this line is intended to show that tower performance deviates from the expected at lower

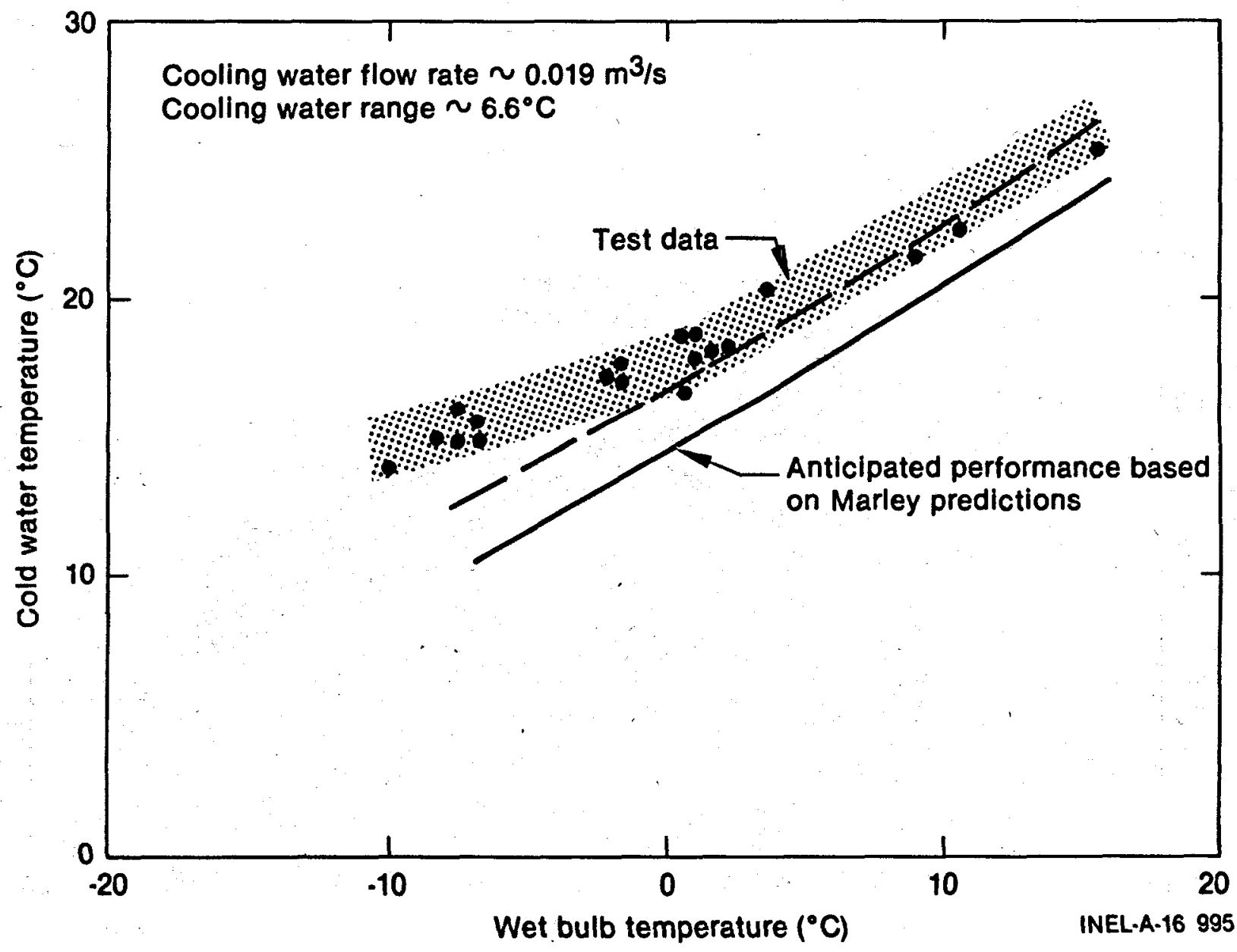

Figure 12. Prototype Power.Plant cooling tower performance. 
temperatures; it is not intended to show exactly where this deviation occurs. Operational experience has shown that ice would begin to form whenever the air temperature (dry bulb) reached $0^{\circ} \mathrm{C}$, which is reasonably consistent with the test data.

The net effect of the buildup of ice in the cooling tower (besides possible structural damage) is warmer cold water temperatures leaving the tower and entering the condenser. These warmer water temperatures result in higher condensing temperatures and turbine exhaust pressures (for the same heat load), which decrease the power output. This effect on power output is shown in Figure 13 where the solid and dashed line and the shaded area represent the same parameters as in Figure 12. These data show that at the colder wet bulb temperatures, the actual performance deviates from 8 to $13 \%$ from the performance expected on the basis of tower performance predictions. In part, this difference is due to the offset between actual and predicted tower performance at warmer air temperatures. If one takes into consideration this offset (shown as a dashed line), the deviation in performance due to icing is 3 to $8 \%$. Although this deviation may not be particularly large, it is important to note that prior to taking a particular data set, the tower was deiced by reversing cooling air flow for a short period of time so that the effects of icing were minimized. (The tower was allowed to operate approximately $1 \mathrm{~h}$ after deicing to allow temperatures to stabilize.) During operation of a commercial plant, this may represent the "best" approach to anticipated performance and, on the average, the deviation may be significantly larger.

Conventional power plants generally operate the cooling system at less than full capacity during

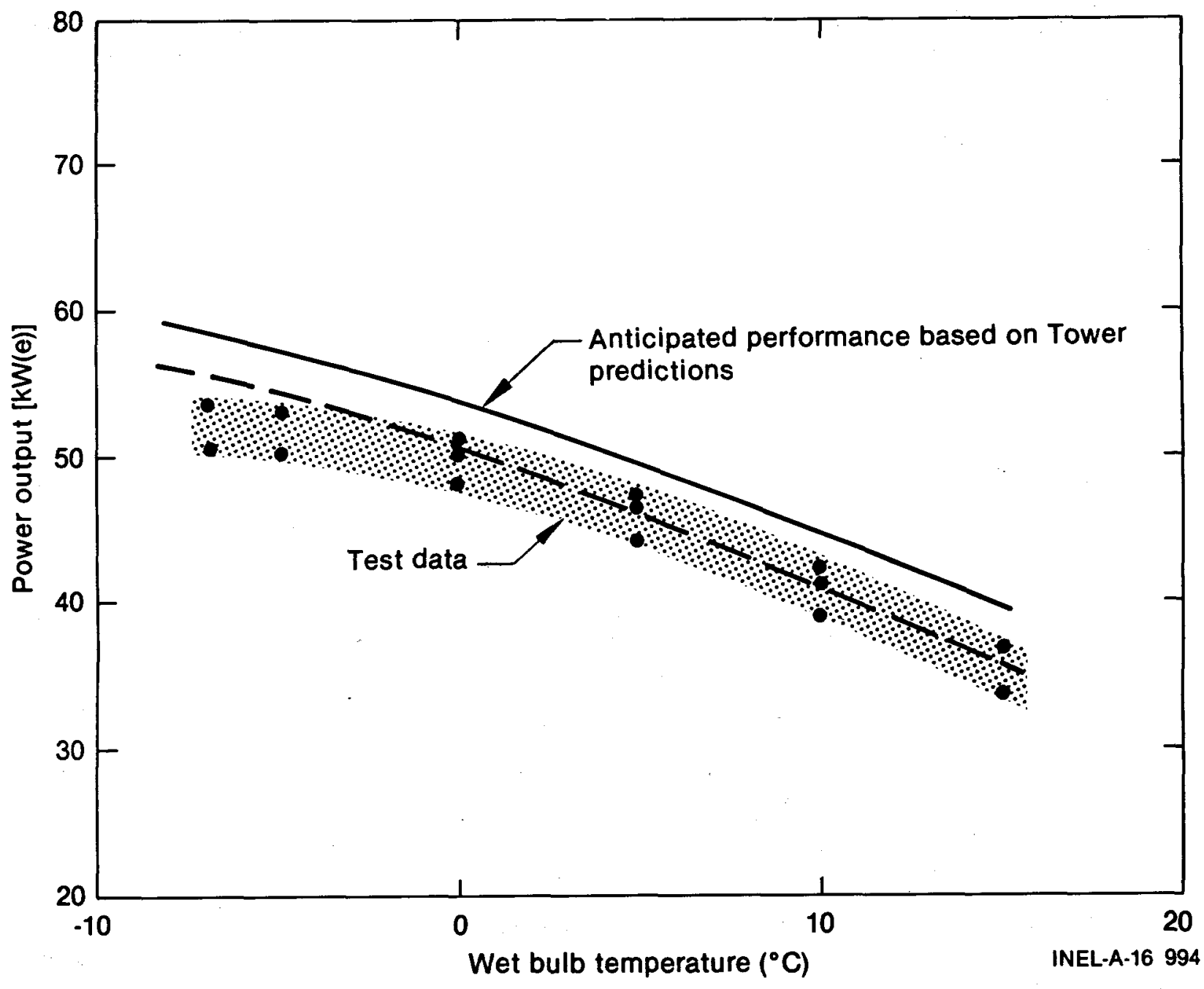

Figure 13. Effect of cold temperatures on tower performance. 
colder periods because they are usually designed for relatively constant turbine exhaust pressures (corresponding to a high wet bulb temperature) and power outputs; thus, the effect of icing on tower performance does not impact overall plant performance (other than possible structural damage to the tower). In geothermal applications where the economics are marginal, the plant may be designed to take advantage of the increased potential to generate power at lower ambient air temperatures. In these applications, it is important to recognize the potential impact of tower icing on plant performance, since these periods represent times of maximum power output, and any deviatiơh in performance can adversely affect the plant economics. Testing with the PPP has shown that the cooling system performance does deviate from the predicted during below freezing temperatures. Although the magnitude of deviation in terms of overall cycle performance for the PPP may be atypical, the trend of reduced performance of the heat rejection system when temperatures are below freezing is not, and should be considered from economical and operational standpoints when designing "floating power" plant cycles and selecting equipment.

\section{System Performance Test Results}

After the isobutane working fluid contaminated with nitrogen was purged from the plant and replaced with "fresh" working fluid, a series of tests were conducted to "map" the performance of the PPP and its components. Prior to running these performance tests, the plant was operated as a thermal loop to check system and component heat balances and identify any problems with the plant instrumentation. A typical thermal loop cycle is shown in Figure 2 and discussed previously in the "Facility Description" section. The thermal loop mode of operation was chosen to check system heat balances and instrumentation because the heat balance calculations are not complicated with the working fluid energy loss in the turbine. Ideally, the expansion through the turbine bypass valve is isenthalpic, and is shown in the thermal loop cycle in Figure 2; the heat added in preheating and boiling the working fluid equals the heat rejected in desuperheating and condensing. Heat balances can therefore be made between the two heat exchangers and between the fluids in each heat exchanger. During these instrument verification tests made prior to conducting the performance tests, the heat balance between the geothermal fluid, the isobutane, and the cooling water systems showed agreement to within less than $5 \%$, and the performance tests proceeded.

Overall System Performance Results. The PPP performance tests were conducted over a wide range of turbine inlet and exhaust conditions dictated by the geothermal fluid flow and temperature and by the ambient air temperatures. The "mapping" of the plant performance was accomplished by fixing the turbine inlet pressure and flow (fixing the geothermal fluid inlet conditions) and varying the cooling water flow rate so that the turbine exhaust pressure varied from the maximum allowable ( $0.724 \mathrm{MPa})$ to the minimum pressure dictated by the condenser heat load and the ambient conditions. This procedure was repeated for several different turbine inlet pressures and flows (different conditions attained by adjusting the geothermal fluid flow rate) until the range of anticipated operating conditions had been covered. The plant performance, given in terms of a power output for the different conditions tested, is summarized in Figure 14, which gives the power output as a function of turbine exhaust pressure for a fixed turbine inlet pressure. Also shown in Figure 14 is the predicted performance of the plant at the design turbine inlet pressure of $2.16 \mathrm{MPa}$ (using predicted turbine efficiencies from Barber-Nichols ${ }^{1}$ ) and the conditions for the maximum power output achieved thus far with the plant, $59 \mathrm{~kW}(\mathrm{e})$.

During the performance tests, the plant was not operated at the design turbine inlet conditions because geothermal fluid flow rate and/or temperatures were not high enough to operate the boiler/preheater at required pressure and flow. To estimate the geothermal fluid flow rate required to produce a particular turbine inlet pressure, test data were organized to show turbine inlet pressure as a function of geothermal fluid conditions (see Figure 15). The geothermal fluid temperature at the plant inlet during the performance tests was 132 to $135^{\circ} \mathrm{C}$. At $135^{\circ} \mathrm{C}$ inlet temperature (see Figure 15), approximately $7.56 \mathrm{~kg} / \mathrm{s}$ of geothermal fluid would be required to produce the design turbine inlet pressure and flow. The maximum geothermal fluid flow reached during this period was $6.73 \mathrm{~kg} / \mathrm{s}$, which resulted in a turbine inlet pressure of $2.12 \mathrm{MPa}$ and a power output of $59 \mathrm{~kW}(\mathrm{e})$ at a turbine exhaust pressure of $0.490 \mathrm{MPa}$. 


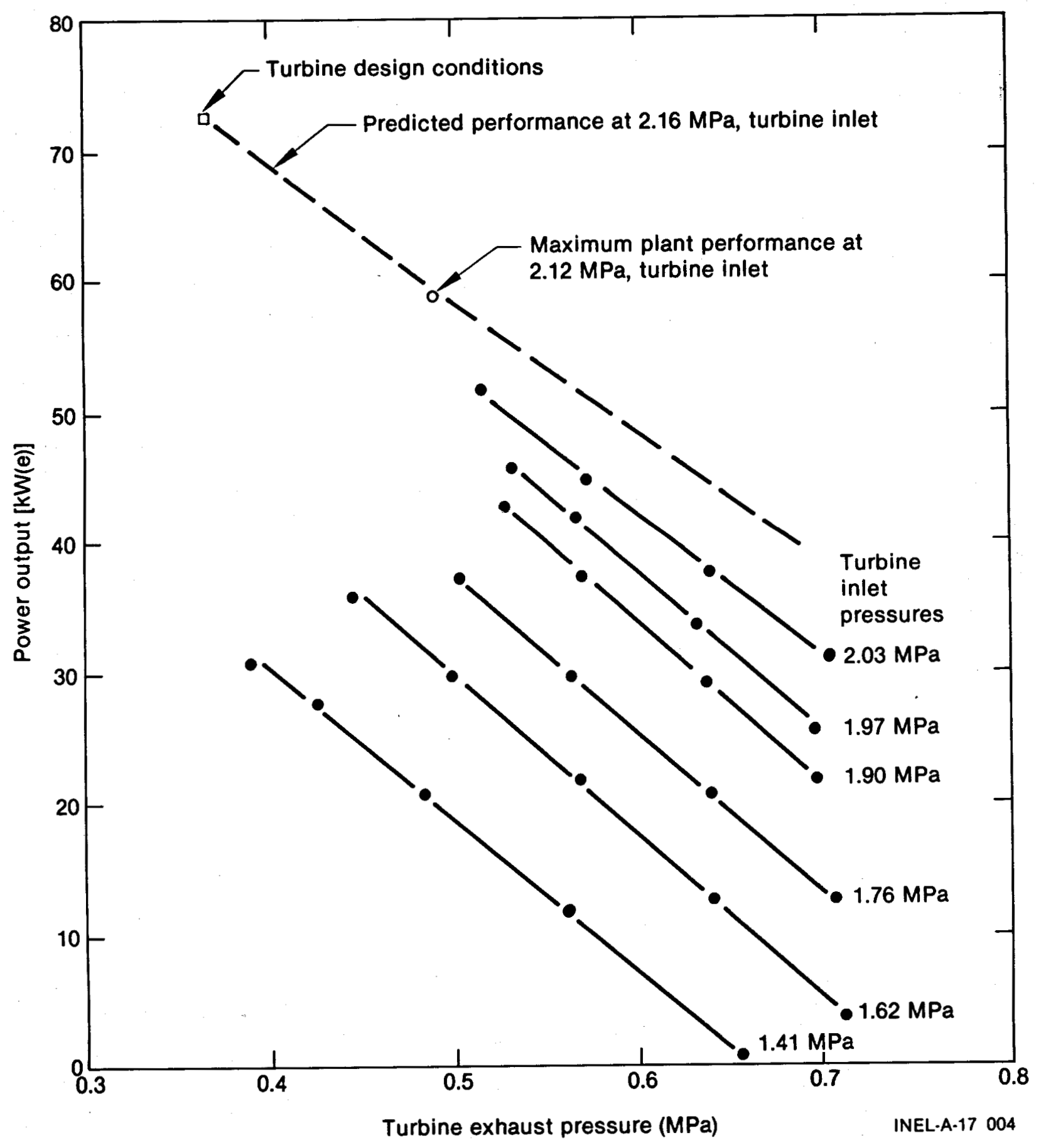

Figure 14. Prototype system performance results. 


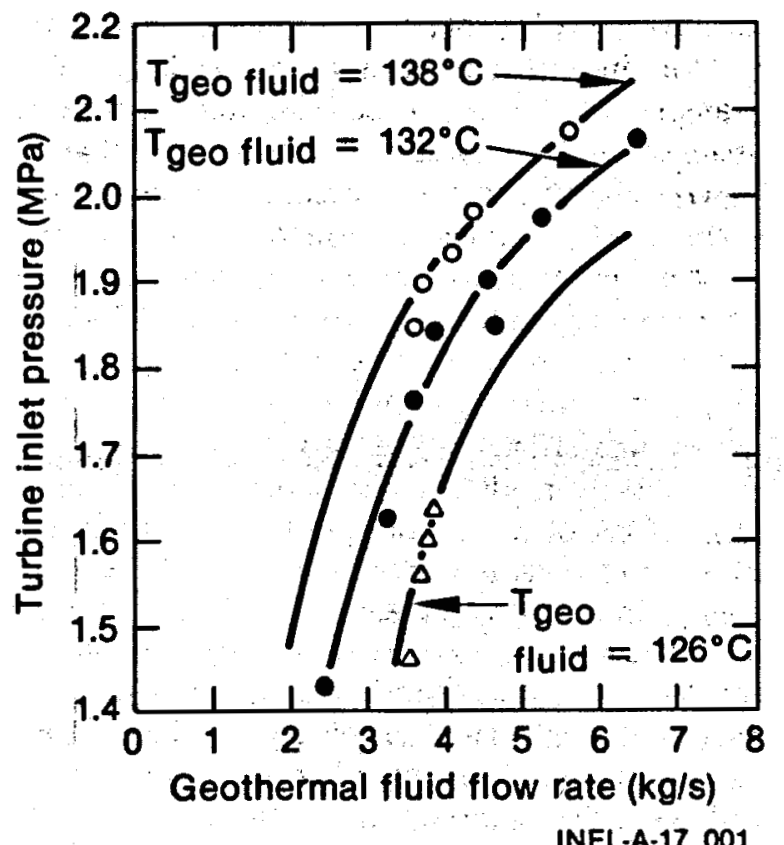

Figure 15. Prototype boiler/preheater performance.

During the operation of the PPP thus far, the turbine exhaust pressure has not approached the design value of $0.365 \mathrm{MPa}$ with the plant operating near the design inlet turbine pressure, even during the winter when the ambient air temperatures were cold. A further discussion of the limitations of the cooling system is given later in this report.

\section{Component Performance}

Turbina-The PPP turbine has a design efficiency of $74 \%$ at a velocity ratio [ratio of tip speed to the isentropic nozzle spouting velocity $\left(\mathrm{U} / \mathrm{C}_{\mathrm{O}}\right)$ ] of 0.4234 and a pressure ratio of 5.91. At the design inlet and exhaust conditions, the turbine has an energy extraction potential of $68600 \mathrm{~J} / \mathrm{kg}$ (isentropic expansion) and a vapor flow rate of $1.638 \mathrm{~kg} / \mathrm{s}$. On the basis of the stated boost pump and motor/generator efficiencies and the gearbox power requirements, it is estimated that the plant would produce approximately $72 \mathrm{~kW}(e)$ if operated at design conditions.

Turbines are generally designed to have the optimum efficiency at the design condition. If the turbine is operated at higher or lower velocity or pressure ratios, the turbine efficiency will decrease, i.e., the efficiency curve has the general shape of an inverted $U$, with the maximum value at the design conditions. The efficiencies of the PPP turbine during the performance tests are shown in Figures 16 and 17 as functions of the

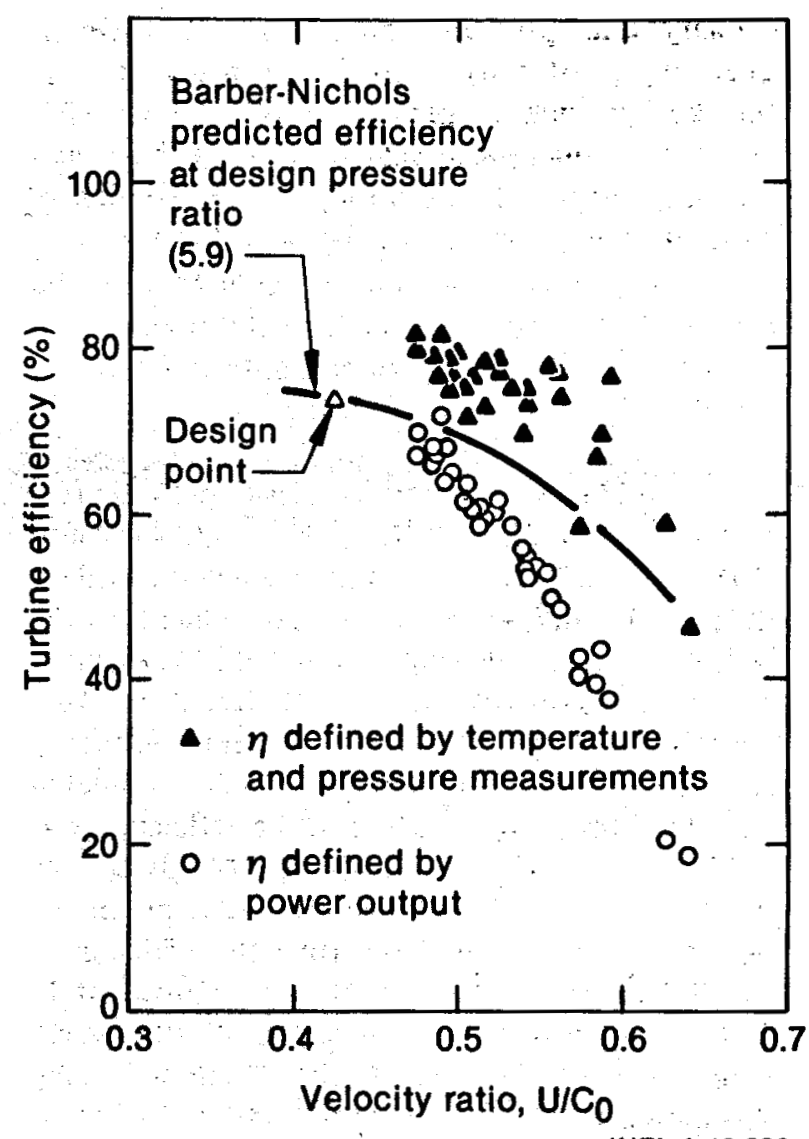

INEL-A-16 996

Figure 16. Prototype turbine performance efficiency versus velocity ratio.

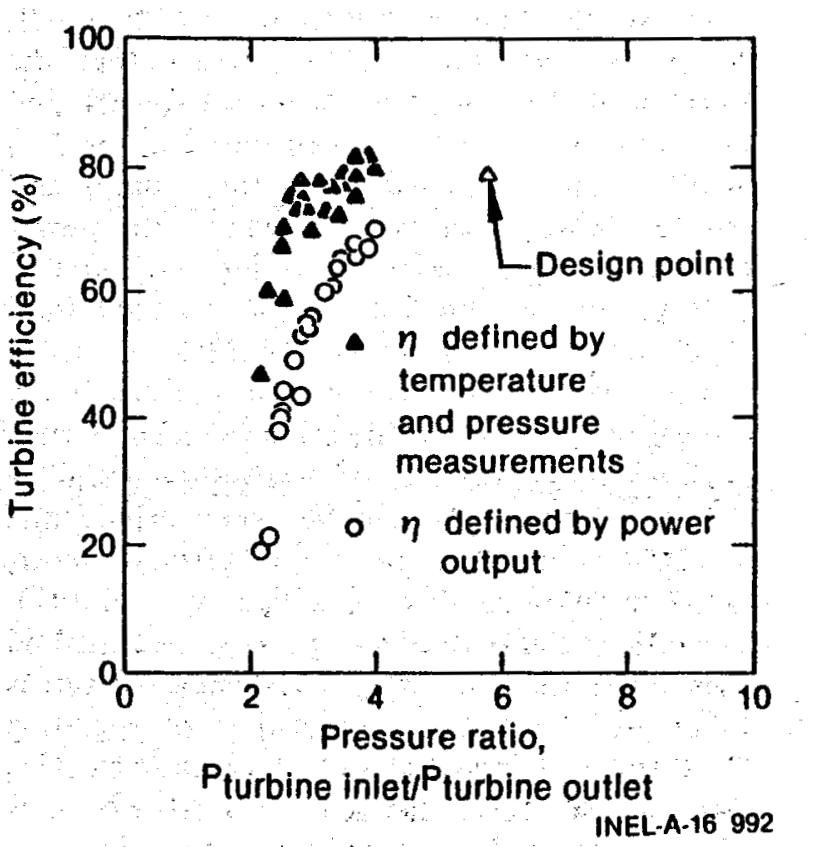

Figure 17. Prototype turbine performance efficiency yersus pressure ratio. 
velocity and pressure ratios for the different operating conditions. Also shown in Figure 16 is the Barber-Nichols prediction of turbine efficiency as a function of velocity ratio at the design pressure ratio ${ }^{1}$. The limitations in the condenser performance did not allow the plant to operate at or near design turbine exhaust pressures while the turbine inlet pressure was at or near design values. As a result, the data obtained only defined one portion of the efficiency curve.

Two methods were used to derive operating turbine efficiency, the results of which are shown in Figures 16 and 17. One method used was based on the pressure and temperature measurements of the isobutane vapor entering and leaving the turbine. These measurements were used to derive an actual enthalpy change and an isentropic enthalpy change of the working fluid vapor using tabulated isobutane properties. ${ }^{2}$ The turbine efficiency was defined as the ratio of the actual enthalpy change to the isentropic enthalpy change. At most of the higher power output cases run, the efficiencies calculated using this method were equivalent to and, in some instances, in excess of the design value of $74 \%$. The efficiencies calculated using this method have considerable "scatter," which is probably due to inaccurate or inconsistent instrument readings, and/or may reflect limits in accuracy when interpolating tabulated isobutane properties.

The second method used to derive turbine efficiency was based on the plant power output, the working fluid vapor flow rate measurements, and the isentropic enthalpy change found in the first method. The estimated generator, pump, and gearbox power losses were added to the power output reading to define a turbine shaft power. This power was divided by the working fluid vapor flow rate to obtain the power per unit mass, which was divided by the isentropic enthalpy change to obtain a turbine efficiency. The results obtained using this method were lower than the efficiencies obtained using measured turbine inlet and exhaust pressures and temperatures; however, they were more consistent (see Figures 16 and 17). The efficiencies derived using this second method were lower than the design efficiency (70 versus $74 \%$ ), which would be expected when operating the turbine at less than design conditions. This method was recommended by Barber-Nichols when reviewing the turbine performance data.

As indicated previously, the data scatter in the efficiencies defined with temperature and pressure measurements is probably the result of inaccurate and/or inconsistent instrument readings. For example, if the vapor entering the turbine is assumed to be saturated instead of slightly superheated $\left(0.6\right.$ to $1.1^{\circ} \mathrm{C}$ according to data), the turbine efficiencies obtained from turbine pressure and temperature readings could decrease approximately $5 \%$, i.e., from 80 to $75 \%$. A similar error in the turbine exhaust temperature, i.e., more superheat than measured, could lower the turbine efficiency (derived from temperature and pressure readings) even more. The relatively large effect of a one- or two-degree error in the measured temperature occurs because of the small change in enthalpy (actual $\Delta \mathrm{h}=46500 \mathrm{~J} / \mathrm{kg}$ or less at lower turbine inlet pressures) through the turbine. A $1200-\mathrm{J} / \mathrm{kg}$ change in enthalpy can change the calculated efficiency by several percent. By comparison, a similar error in measured turbine inlet conditions for a flash steam cycle would introduce an error in indicated turbine efficiency of only about $2300 \mathrm{~J} / \mathrm{kg}$ out of 325500 , or $0.7 \%$.

Another possible cause for the difference in magnitude of the calculated efficiencies is the error in the measurement of the isobutane vapor flow rate. The vapor flow is measured using an orifice plate and differential pressure transmitter calibrated for saturated isobutane vapor flow at $1.638 \mathrm{~kg} / \mathrm{s}$ and $1044^{\circ} \mathrm{C}(2.16 \mathrm{MPa})$. Since these conditions (flow, temperature, and pressure) were not reached during testing, the flow rate readings were corrected (density correction) to actual conditions to determine the "measured" flow rate. To confirm these readings, vapor flow through the turbine was predicted using the turbine nozzle dimensions and assuming a saturated vapor entering the turbine and choked flow through the nozzle (the turbine nozzles operated in a choked condition; exhaust pressure did not affect flow rate). The predicted and measured flow rates are shown in Figure 18 as a function of turbine inlet pressure. The predicted flow rate at design turbine pressure $(1.654 \mathrm{~kg} / \mathrm{s})$ agrees very well with the Barber-Nichols design value of $1.638 \mathrm{~kg} / \mathrm{s}$. The predicted flow rates assume a discharge flow coefficient of unity (typical values would be 0.95 to 0.99 ). The difference between measured and predicted flow rates in Figure 18 is approximately 5.5 to $6 \%$, and probably can be attributed to the accuracy of the instruments and the accuracy limitations in interpolating the tabulated isobutane properties. ${ }^{2}$ If the actual flow rate is lower than the measured flow rate (as indicated by the prediction), the turbine efficiency 


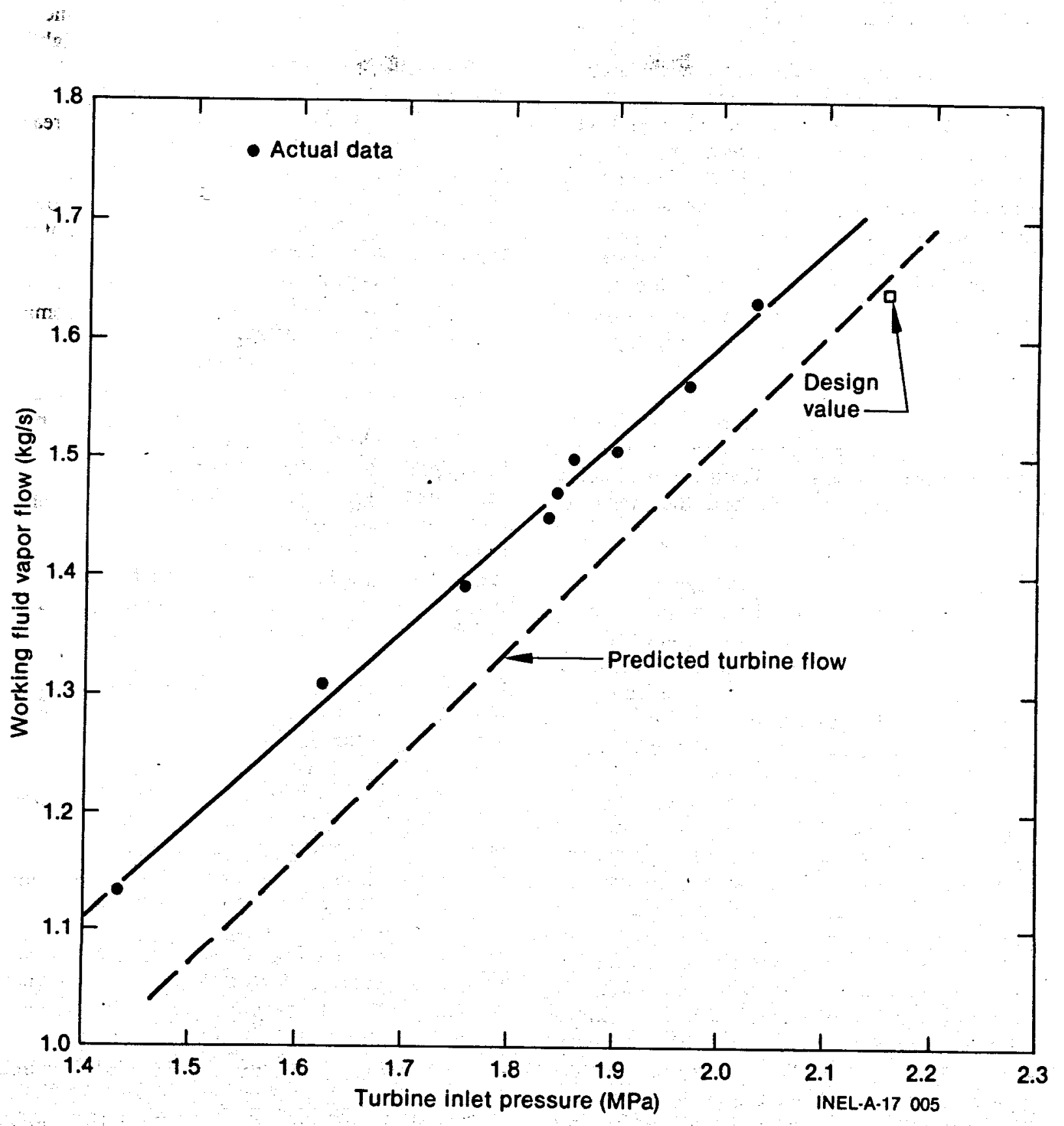

Figure 18. Turbine vapor flow rate, actual and predicted. 
calculated using the plant power output would be higher because the turbine shaft power would be divided by a smaller mass flow rate.

This discussion of the difference in magnitude of the calculated turbine efficiencies is not meant to discount the data taken; rather, it is intended to show that in binary cycles it is necessary to obtain accurate, repeatable data if consistent results are to be obtained. Monitoring the performance of a binary turbine will be difficult without accurate data, and the designer of binary systems, especially experimental, should be aware of the sensitivity of calculated or measured turbine performance to small errors in instrument measurements.

In general, the calculated turbine efficiencies behave as expected; that is they increase as the turbine approaches design conditions, and indicate the plant is operating at or near the predicted efficiency.

Cooling System-The limiting factor in the production of power from the Prototype Power Plant is the condenser. The existing condenser is a surplus unit instead of a heat exchanger designed specifically for this application. The design of the existing condenser requires that the lower end of the tube bundle (approximately 0.61 to $0.76 \mathrm{~m}$ ) be immersed in liquid. This effectively reduces the heat exchanger area available for condensing and increases the heat load for the unit, since this liquid is subcooled before leaving the condenser. A temperature profile of the cooling system versus time is shown in Figure 19. These data were taken during operation in December 1979 when the plant was operating at a turbine inlet pressure of 1.896 to $2.034 \mathrm{MPa}$ and producing 40 to $55 \mathrm{~kW}(\mathrm{e})$. In this figure, condensing temperature was taken as the temperature of saturated isobutane corresponding to the measured condenser pressure. It is apparent from the data that the condenser was not effectively utilizing the potential of the ambient air. It should also be noted that the amount of apparent subcooling occurring in the condenser (see Figure 19) is approximately $8.3^{\circ} \mathrm{C}$. If the plant had been constructed with a condenser providing a $5.6^{\circ} \mathrm{C}$ pinch point between the cooling water leaving the unit and the condensing temperature, the condenser pressure would have been from 0.380 to $0.410 \mathrm{MPa}$ instead of 0.480 to $0.520 \mathrm{MPa}$. At these lower condenser pressures, the plant power output would have increased from 55 to $65 \mathrm{~kW}$ (e) (estimated using data results in Figure 14).

\section{Comparison of Measured and Calculated System Performance}

One of the purposes of the performance tests was to enable verification that the performance of the plant could be predicted, even when not operating at the design turbine conditions. To predict the performance of the plant, it was necessary to relate a given set of geothermal fluid and cooling water conditions at the inlet of the plant to a turbine inlet pressure, vapor flow rate, and turbine exhaust pressure. With the turbine inlet and outlet conditions determined, power output can be calculated assuming turbine efficiency, gearbox losses, pumping power, and motor/generator efficiency.

Prediction Method. The configuration of the boiler/preheater makes analytical prediction of performance very difficult. Since this configuration is not typical of one that might be used in a full-scale plant application, no further effort was spent in a detailed analysis of the heat exchanger. Instead, test data were used to relate the geothermal fluid flow and temperature to the turbine inlet pressure (see Figure 15). For a given geothermal fluid temperature, between 126 and $138^{\circ} \mathrm{C}$, and fluid flow rate, one can estimate the turbine inlet pressure from the curves given in Figure 15.

In reviewing the performance of the turbine, the flow of isobutane vapor through the turbine was predicted as a function of the turbine inlet pressure, assuming a saturated inlet vapor and choked flow through the nozzle. This prediction of vapor flow as a function of turbine inlet pressure is shown in Figure 18. With the predicted vapor flow curve in Figure 18, the plant power output can be defined as a function of turbine exhaust pressure for a fixed turbine inlet pressure,given the turbine skid efficiencies and parasitic power requirements. The turbine efficiency for the calculations was taken from the Barber-Nichols prediction given in Figure 16. The results of the calculations of predicted power output as a function of turbine inlet and exhaust pressures are given in Figures 20 and 21. Shown in Figure $\mathbf{2 0}$ are predicted and actual performance data for three cases of turbine inlet pressure and a predicted performance curve at the design turbine inlet pressure. At the lower turbine exhaust pressures, actual performance and predicted performance curves approach each other, and for the 1.41-MPa inlet pressure, actual performance exceeds predicted performance. At higher turbine 


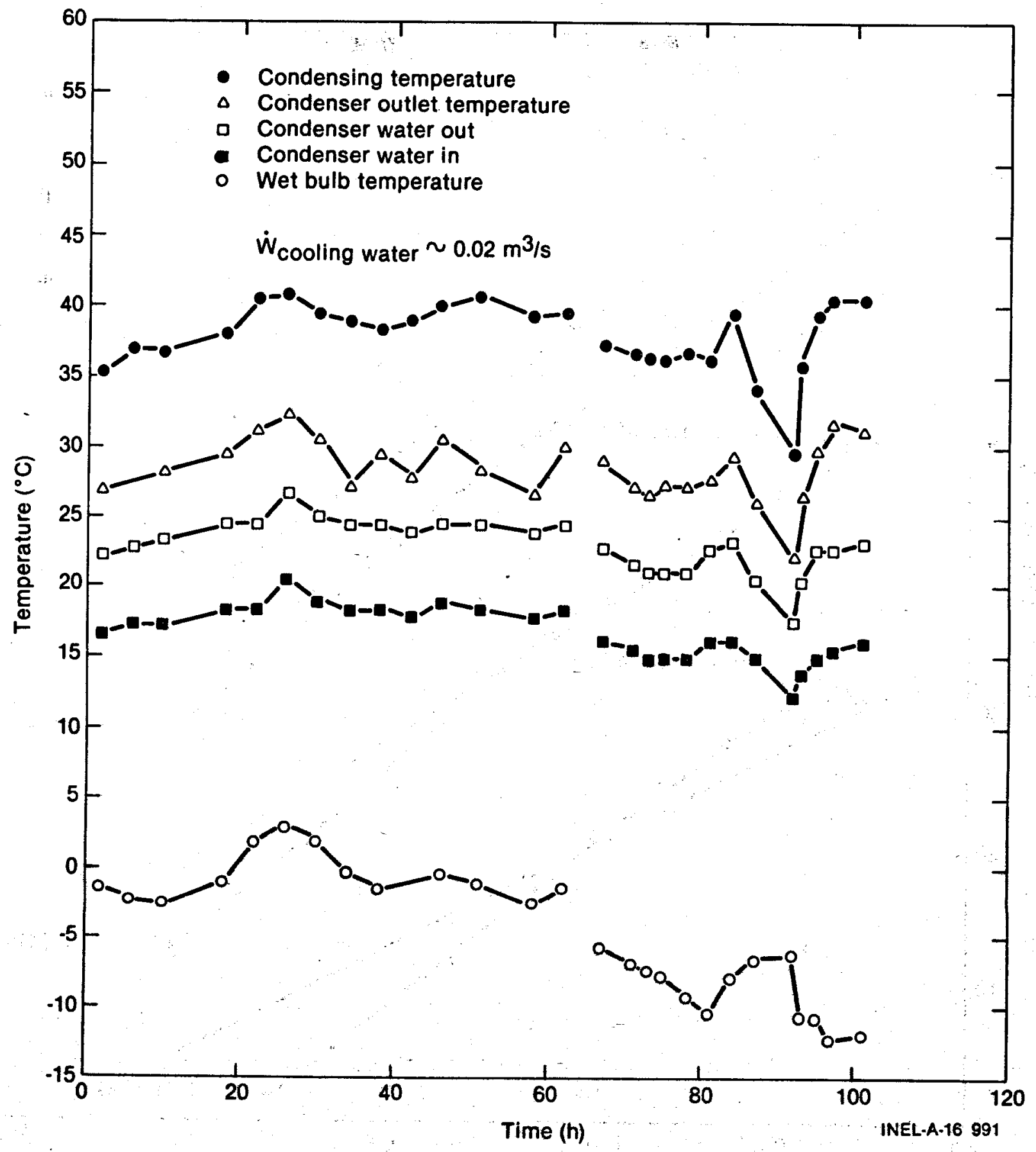

Figure 19. Cooling system temperature profile. 


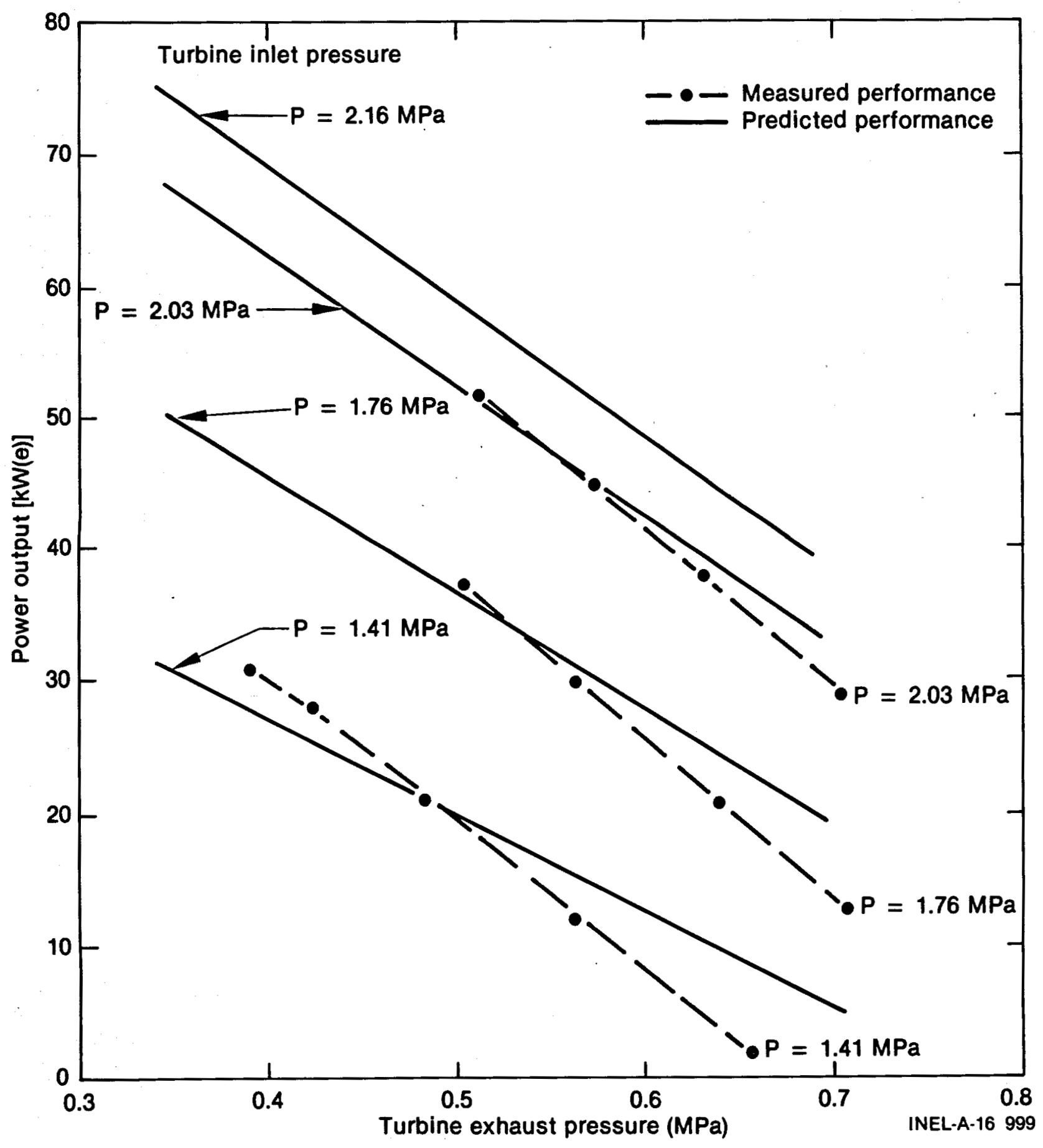

Figure 20. Predicted prototype system performance. 


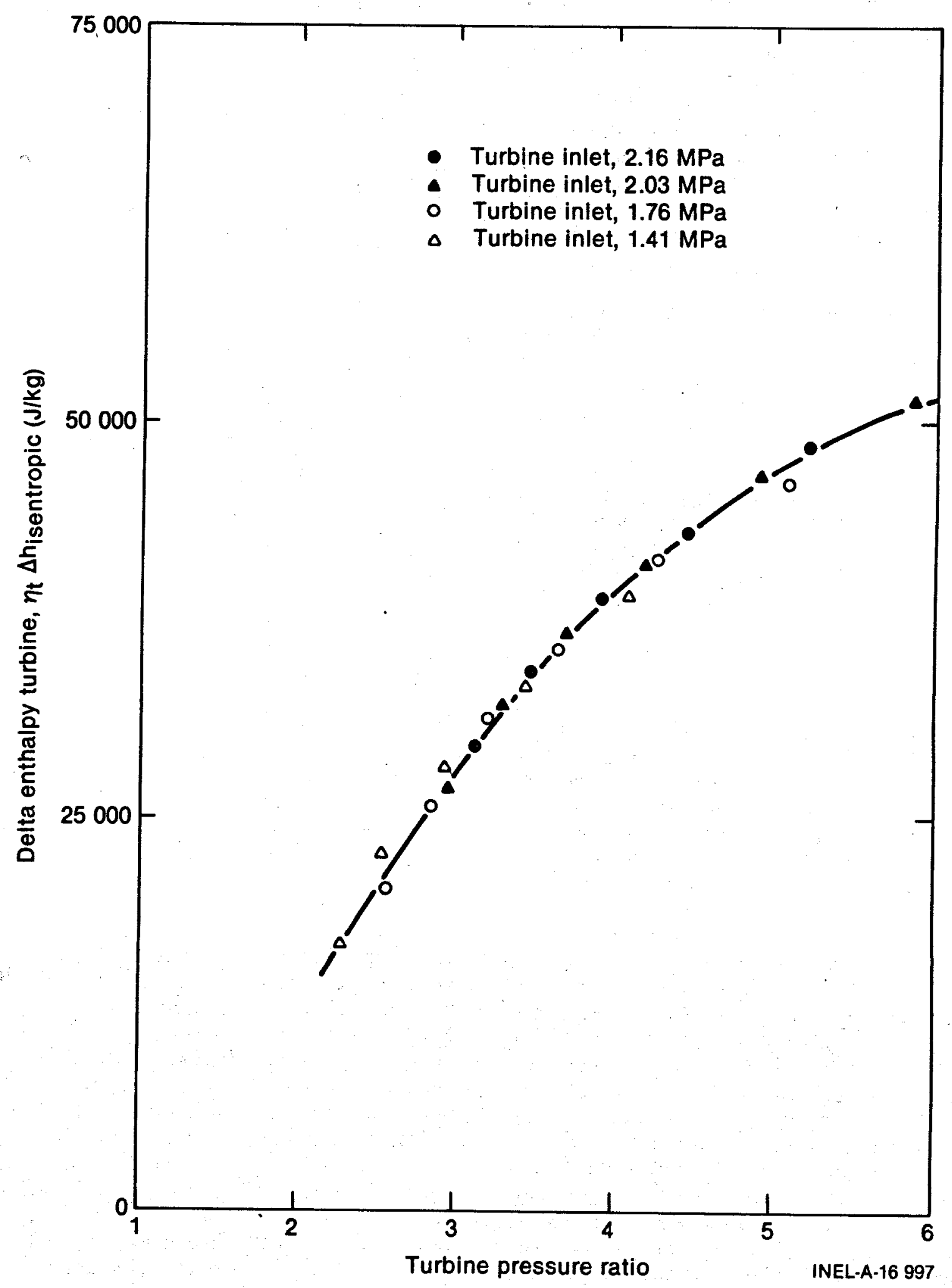

Figure 21. Predicted turbine performance. 
exhaust pressures, the actual performance is decreasing at a faster rate than the predicted performance. This would be expected because the predicted efficiencies are for a pressure ratio fixed at the design value and a variable velocity ratio, whereas in actual operation of the plant, both the pressure and velocity ratios vary (if turbine inlet conditions are kept at or near saturation conditions). Because both the pressure and velocity ratios are moving away from the design values at higher exhaust pressures, the actual efficiency is decreasing more rapidly than the predicted value. At lower exhaust pressures, the actual and predicted performance compare favorably, which would be expected since the actual and predicted efficiencies more closely agree at the lower velocity ratios corresponding to these exhaust conditions (see Figure 16).

The results of the calculations for predicting turbine performance are summarized in Figure 21. The relationship between the turbine work per unit mass and the turbine pressure ratio shown in the figure is interesting, in that this turbine work is primarily a function of the pressure ratio, and does not deviate significantly with turbine inlet pressure.

Although the condenser is physically identical to the boiler/preheater, it is possible to estimate the thermal performance of the unit if the subcooling is discounted. The data taken during the performance tests at a fixed cooling water flow rate $\left(0.021 \mathrm{M}^{3} / \mathrm{s}\right)$ and various turbine inlet pressures were used to define an effective UA (product of overall heat transfer coefficient and heat transfer area) for condensing in the condenser as a function of the vapor flow rate. The results of these calculations are shown in Figure 22. These calculated UA values were then used to define the cooling water temperature required to produce a given condenser pressure at a given heat load. The condenser heat loads were defined at selected turbine inlet and exhaust conditions using predicted isobutane vapor flow rates (Figure 18) and predicted turbine efficiencies (Figure 16). The condenser heat load, UA values, and condensing temperature were then used to define the cooling water temperatures. The resulting relationship between condenser pressure and cooling water temperature at the condenser inlet is shown in Figure $\mathbf{2 3}$ for various turbine inlet pressures. These results are valid only for the assumed cooling water flow rate of $0.021 \mathrm{~m}^{3} / \mathrm{s}$.

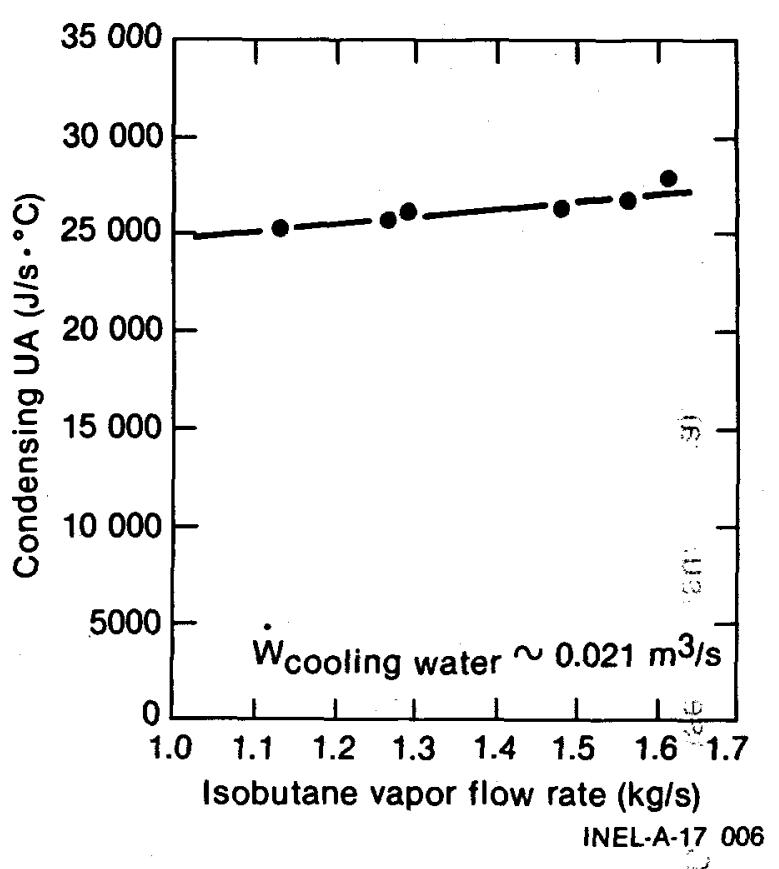

Figure 22. Prototype condenser performance data.

Prediction Example. These predictions of system and component performance can be used to predict or verify the plant power output given the geothermal fluid and cooling water conditions. The following example will illustrate how the projections of component performance can be used by attempting to verify the plant power output from a set of data taken December 11, 1979. For this set of data, the geothermal fluid entered the plant at $0.0071 \mathrm{~m}^{3} / \mathrm{s}(6.58 \mathrm{~kg} / \mathrm{s})$ and $135^{\circ} \mathrm{C}$. The cooling water entered the condenser at $15^{\circ} \mathrm{C}$ and at a flow rate of $0.021 \mathrm{~m}^{3} / \mathrm{s}$. From Figure 15 , the turbine inlet pressure is estimated to be 2.10 $\mathrm{MPa}$ for the geothermal fluid inlet conditions. At this turbine inlet pressure, the predicted working fluid vapor flow (Figure 18) is $1.61 \mathrm{~kg} / \mathrm{s}$. Next, the condenser pressure is found from Figure 23. At a turbine inlet pressure of $2.10 \mathrm{MPa}$ and a cooling water inlet temperature of $15^{\circ} \mathrm{C}$, the predicted condenser pressure is $0.507 \mathrm{MPa}$. At the turbine pressure ratio of 4.15 , a turbine work of $40500 \mathrm{~J} / \mathrm{kg}$ of working fluid is found using Figure 21. The turbine shaft power output of $65.21 \mathrm{~kW}$ is adjusted for parasitic losses in the turbine gearbox $(3.36 \mathrm{~kW})$, the boost pump and belt drive $(1.44 \mathrm{~kW})$, and the motor/generator efficiency $(91 \%)$ to get a predicted power output of $55 \mathrm{~kW}(\mathrm{e})$. The actual power output for this particular data was $57 \mathrm{~kW}(\mathrm{e})$, which agrees well with predicted plant performance. These methods 


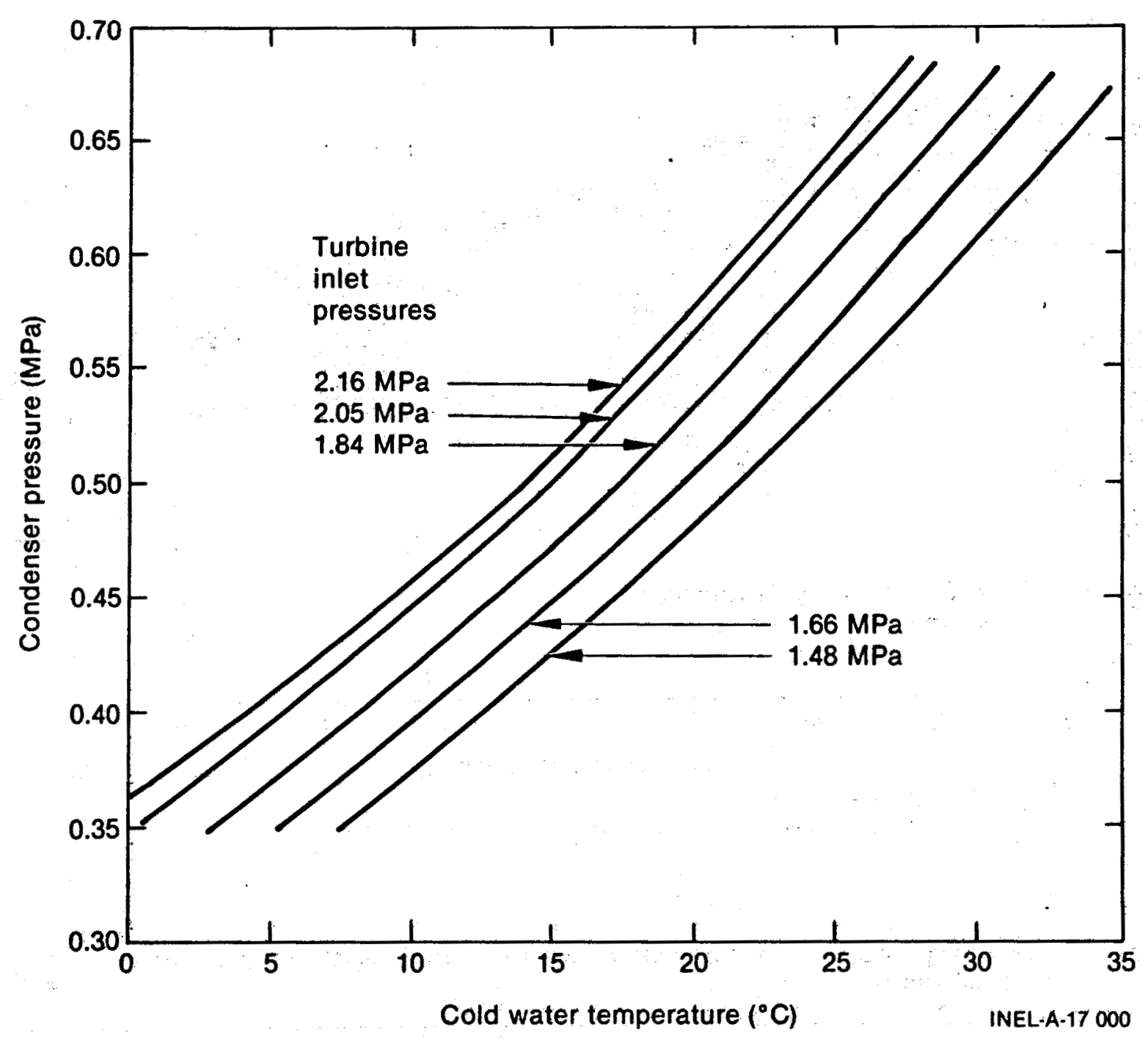

Figure 23. Predicted condenser performance.

for predicting plant performance work reasonably well when the plant is operating at or near design conditions.

\section{Condenser Degradation- Noncondensable Gases}

The operational history of the condenser degradation due to the contamination of the isobutane with nitrogen was reviewed in the section on "Plant Operation" and is also shown graphically in Figure 24. The data in Figure 24 show how the condenser pressure began to increase (between day 35 and day 40), even though the cold water temperatures remained relatively constant, and how the condenser performance improved when the working fluid was replaced on day 70. When it was discovered that the degradation in condenser performance was not due to fouling of condenser tube surfaces exposed to the cooling water, it was suspected that the working fluid had become contaminated or had degraded in some manner. To verify the degradation of the working isobutane, samples were taken from the plant and from unopened cylinders of working fluid. The samples taken were two-phase; i.e., liquid and vapor, so that their pressure would correspond to the saturation pressure of the fluid at the sample temperature. The samples were placed in a.water bath and the sample pressure and water temperature recorded. The results of this sampling are shown in Table 5.

The results of these sampling tests indicated that the fluid was contaminated, and the decision was made to replace it. Before replacing the working 


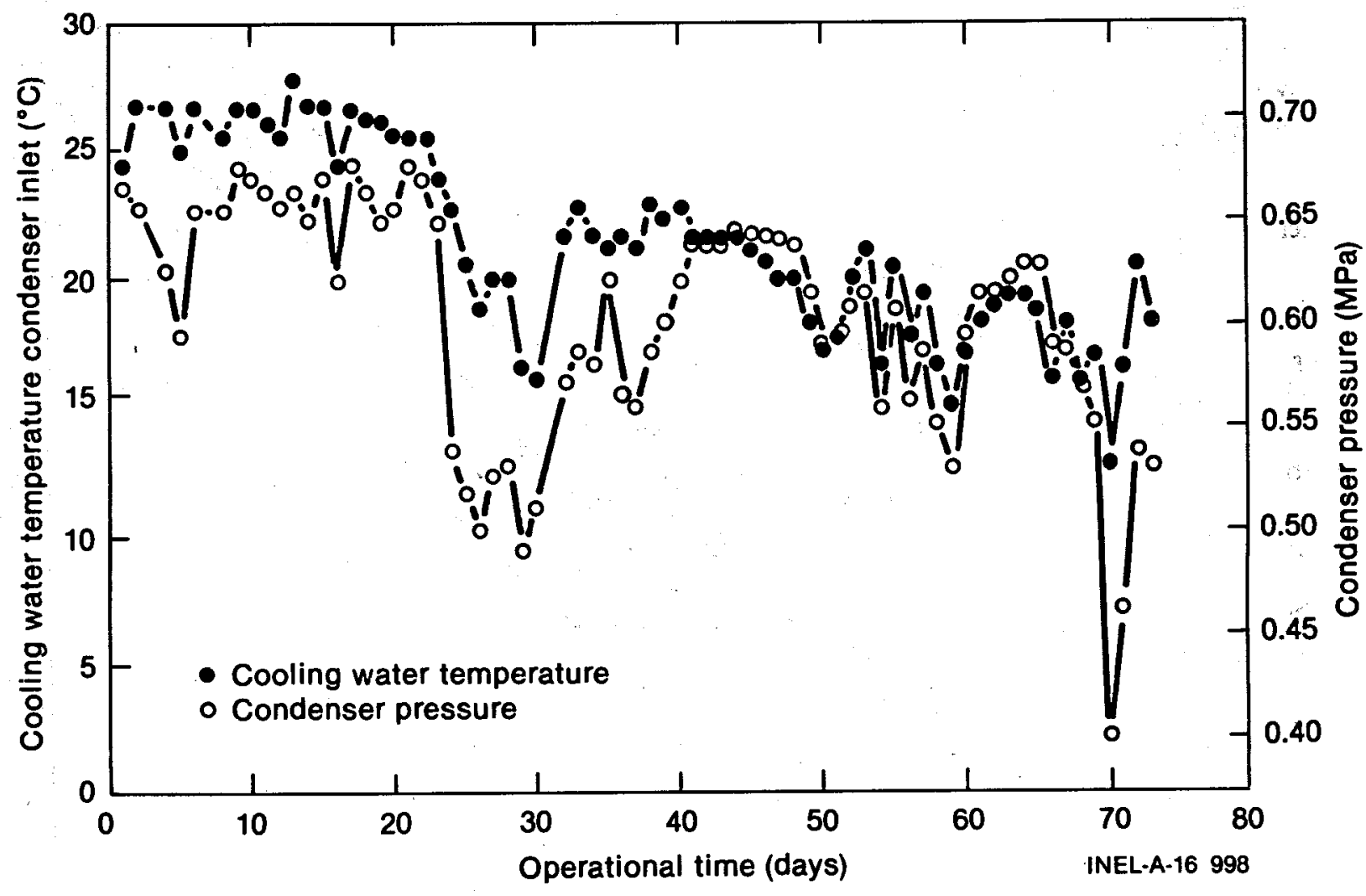

Figure 24. Prototype condenser performance degradation due to noncondensable gases.

Table 5. Prototoye Power Plant working fluid samples, pressure-temperature relationships

\begin{tabular}{llccc}
\hline Date & Sample Location & $\begin{array}{c}\text { Water } \\
\text { Temperature } \\
\left({ }^{\circ} \mathrm{C}\right)\end{array}$ & $\begin{array}{c}\text { Saturated } \\
\text { IC }_{4} \text { Pressure } \\
(\mathrm{MPa})\end{array}$ & $\begin{array}{c}\text { Sample } \\
(\mathrm{MPa})\end{array}$ \\
\cline { 3 - 4 } $11-1-79$ & Storage tank & 27.2 & 0.372 & 0.474 \\
$11-1-79$ & New $\mathrm{IC}_{4}$ cylinder & 27.2 & 0.372 & 0.367 \\
$11-2-79$ & Storage tank & 30 & 0.402 & 0.527 \\
$11-2-79$ & New cylinder & 30 & 0.402 & 0.414 \\
$11-2-79$ & Condenser & 11.1 & 0.228 & 0.293 \\
$11-7-79$ & Storage tank & 13.9 & 0.248 & 0.352 \\
$11-7-79$ & New cylinder & 13.9 & 0.248 & 0.248 \\
$11-7-79$ & Condenser & 13.3 & 0.244 & 0.294 \\
\hline
\end{tabular}


fluid, a sample was taken from storage and sent to Phillips Chemical for analysis. This analysis (shown in Table 6) confirmed the presence of nitrogen in the working fluid, and showed that, except for the nitrogen, the liquid isobutane still met the specification for aerosol-grade propellant. After approximately $1350 \mathrm{~h}$ of operation, no apparent degradation of the isobutane had occurred.

If the air in the liquid analysis is assumed to be all nitrogen (a reasonable assumption on the basis of vapor analysis), then the partial pressure of nitrogen required to have 0.072 mole $\%$ nitrogen in solution in isobutane is $0.074 \mathrm{MPa}$. This calculation is based on the Henry's constant for the equilibrium solubility of nitrogen in isobutane. ${ }^{3}$ The calculated nitrogen partial pressure using the vapor analysis was $0.072 \mathrm{MPa}$. This calculation was made using Dalton's law of partial pressures and the assumption that the remaining vapors were isobutane at a room temperature of $24^{\circ} \mathrm{C}$.

The results show that the method used to indicate whether or not noncondensables might be present, i.e., checking the relationship between temperature and pressure of a two-phase sample, did show that nitrogen was present and provided a reasonable indication of the magnitude $(0.048$ to $0.062 \mathrm{MPa}$ partial pressure of nitrogen compared to 0.069 to $0.076 \mathrm{MPa}$ calculated from chemical analysis). These results show that the use of nitrogen in a binary plant can degrade the performance of the plant, and, as such, it should be used sparingly.

The effect of the nitrogen entering the plant with the makeup isobutane from storage (see "Plant Operation") was a marked increase in condenser pressure and a decrease in power output.
The potential of nitrogen contamination should be recognized by the designers and operators of binary plants, especially those using direct-contact heat exchangers where the working fluid is exposed to the geothermal fluid. In those instances in which the geothermal fluid has considerable quantities of dissolved nitrogen, some means must be provided to vent the noncondensable gas from the condenser. The possible introduction of noncondensables into the condenser is one of the disadvantages of direct-contact heat exchangers, in that additional costs are required to replace and/or recover the working fluid vented with the noncondensable gas. Future direct-contact tests with the PPP will include the installation of a vent and secondary recovery condenser on the vent stream to remove noncondensable gases and minimize working fluid losses.

\section{Performance Summary and Conclusions}

The performance of the Prototype Power Plant can be summarized as follows:

1. When the geothermal fluid was available and operation did not interfere with other site activities, the PPP operated approximately $87 \%$ of the time.

2. Power output variations due to daily ambient air temperatures were found to be approximately 25 to $30 \%$ during the summer and 10 to $15 \%$ during the winter. These power variations are typical of binary plants, and demonstrate that if binary power plants are to take advantage of the increased cooling potential during the winter, the turbine must be designed for

\section{Table 6. Chemical analysis of Prototype Power Plant working fluid}

\begin{tabular}{cccc}
\hline \multicolumn{2}{c}{ Liquid Phase } & \multicolumn{2}{c}{ Vapor Phase } \\
Constituent & Mole Percent & Constituent & Volume Percent \\
\cline { 3 - 4 } & & & 0.09 \\
Air & 0.072 & & $\begin{array}{c}\text { Oxygen } \\
\text { Propane }\end{array}$ \\
Isobutane & 0.399 & Nitrogen & 17.58 \\
A-butane & 95.253 & Hydrocarbon vapor & Remainder \\
\hline
\end{tabular}


performance over a range of exhaust pressures rather than at a specific velocity or pressure ratio.

3. The maximum plant power output was $59 \mathrm{~kW}(e)$ at a turbine inlet pressure of 2.12 $\mathrm{MPa}$ and a turbine exhaust pressure of $0.490 \mathrm{MPa}$. The design plant power output was $73 \mathrm{~kW}(\mathrm{e})$ at a $2.16-\mathrm{MPa}$ turbine inlet pressure and a $0.365-\mathrm{MPa}$ exhaust pressure. Although the plant did not reach design turbine inlet conditions because sufficient geothermal fluid flow and temperatures were not available, the primary reason the plant power output did not reach design conditions (on the basis of turbine design) resulted from the limitations of the surplus condenser. Extremely cold weather would be required to approach the design condensing conditions with this condenser at the rated turbine inlet pressure and vapor flow (from Figure 23, a cooling water condenser inlet temperature of $0.6^{\circ} \mathrm{C}$ would be required).

4. Although the plant never achieved design turbine inlet and exhaust pressures (and corresponding velocity and pressure ratios), the turbine efficiencies were equivalent to and, in some instances, exceeded the values predicted by the
Barber-Nichols Company when turbine conditions approached design values.

5. If an accurate determination of a binary turbine performance is desired, accurate and repeatable instrument measurements are necessary because of the relatively small enthalpy change (compared to steam cycles) across the turbine.

6. The performance of the PPP could be predicted, given the geothermal fluid and cooling water conditions (provided the plant was operating near the turbine design velocity and pressure ratio).

7. The degradation in condenser and plant performance during the auto-run test phase was due to the contamination of the working fluid with nitrogen. The nitrogen gas collected in the condenser while the plant was running and added partial pressure $(0.069$ to $0.076 \mathrm{MPa})$ to the saturation pressure of isobutane at the condensing temperature. The chemical analysis of the isobutane from the plant indicated the presence of nitrogen and showed that, after $1350 \mathrm{~h}$ of operation, the isobutane still met the specifications (except for the nitrogen) for an aerosol-grade isobutane propellant. 


\section{REFERENCES}

1. Memorandum from T. J . Elliot, Barber-Nichols Engineering, to G. Mines, EG\&G Idaho, Inc., Subject: Turbine Data Reduction, August 1, 1980.

2. ASHRAE Thermodynamic Properties of Refrigerants, New York: American Society of Heating, Refrigerating and Air Conditioning Engineers, Inc., 1969, pp. 261-265.

3. O. J. Demuth, Analysis of Binary Thermodynamic Cycles for a Moderately Low-Temperature Geothermal Resource, TREE-1365, July 1979, p. 39. 